\title{
BAUTISTAS Y PRESBITERIANOS \\ EN LA POLÍTICA RELIGIOSA \\ DE FRANCISCO J. MÚGICA \\ Y SIDRONIO SÁNCHEZ PINEDA, 1920-1924
}

\author{
Leticia Mendoza García \\ Universidad Michoacana de San Nicolás de Hidalgo
}

\section{INTRODUCCIÓN}

F n materia religiosa, el contexto federal entre 1920 y 1924 fue Luna etapa convulsa en la que el presidente Álvaro Obregón tuvo que lidiar con el creciente anticlericalismo de los constitucionalistas. Si bien es cierto que Obregón se ajustó a las circunstancias políticas del momento siendo radical cuando convenía y moderado cuando se necesitó, ${ }^{1}$ el problema religioso escaló peldaños peligrosos en algunos estados donde los gobernadores aplicaron de manera conveniente la reglamentación en materia de culto, en algunas ocasiones sancionando la desobediencia y en otras permitiendo la libre conducta del clero. Por otra parte,

Fecha de recepción: 21 de agosto de 2016

Fecha de aceptación: 18 de noviembre de 2016

${ }^{1}$ En materia de educación comprendió perfectamente que, a pesar de que el clero católico era una amenaza para la sociedad porque por medio de las escuelas realizaba una propaganda antirrevolucionaria, la realidad dictaba que no había suficiente dinero ni instalaciones para que el Estado impartiera enseñanza elemental. Para Obregón era "preferible que [los niños] reciban alguna instrucción a que crezcan como analfabetas". ScotT, La sal de la tierra, p. 41. 
con las Iglesias no católicas Obregón mantuvo relaciones cordiales - lo mismo hicieron los gobernadores en sus estadosno porque fuera partidario del protestantismo sino por mera conveniencia política. De esta forma no opuso ningún obstáculo al proselitismo evangélico, lo que le granjeó la simpatía de las misiones, las cuales, por regla general, se congratularon de la política constitucionalista. ${ }^{2}$

En Michoacán, el protestantismo estaba representado por los presbiterianos del norte (Zitácuaro 1876-1919), los metodistas del sur (Morelia 1880-1919), los bautistas del sur (Morelia 1893) y por los presbiterianos del sur (1919). ${ }^{3}$ Durante el porfiriato las

2 Meyer, La Cristiada, pp. 135-137, 193-197. En 1924 la American Protestant Lodge felicitó a Carranza por seguir aplicando una política anticlerical y aprovechó para externarle su deseo de establecer una sucursal en México. Asimismo, como parte de una estrategia diplomática, Obregón financió a la Young Men’s Christian Association (YMCA) [Asociación Cristiana de Jóvenes] y permitió que más de 200 misioneros estadounidenses ingresaran al país. Este hecho generó críticas del obispo de Tacámbaro, Lara y Torres, quien dijo que la YMCA había sido beneficiada con recursos del Estado con el único objetivo de "atraer incautos y descatolizarlos". LARA y Torres, Documentos para la bistoria, p. 285. La YMCA fue creada en Inglaterra en 1844 como un organismo de jóvenes enfocado a fortalecer el cristianismo durante la revolución industrial. Con el tiempo se incorporaron programas físico deportivos como el básquetbol y el voleibol. La Asociación Cristiana de Jóvenes inició actividades en México en 1892, durante el porfiriato. “YMCA México”, en www.ymca.org. $\mathrm{mx} /$ historia.html.

3 El protestantismo en el estado de Michoacán lo he trabajado a partir de mis tesis de maestría y doctorado abarcando un espacio temporal de 1876 a 1932. En ellas he analizado el establecimiento de las misiones metodistas, presbiterianas y bautistas, sus espacios escolares y programas de estudio, la composición social de los miembros, la geografía de las congregaciones, las estrategias de difusión misionera y el anticlericalismo de los miembros. He analizado también el papel que desempeñaron dentro de la política religiosa de las autoridades y la forma en que los protestantes reaccionaron a ella. Aunque con ciertos matices, puesto que no constituyeron un grupo homogéneo, en términos generales el protestantismo en Michoacán fue marcadamente porfirista, maderista y constitucionalista; se ajustó en todo momento a los gobiernos anticlericales atendiendo a diversos intereses particulares, en algunas ocasiones para conservar 
misiones tuvieron un crecimiento constante y sin más contratiempos que los brotes de intolerancia religiosa de parte del clero y sectores católicos. Durante la transición política al maderismo, así como dentro de los primeros gobiernos constitucionalistas, el protestantismo no sufrió cambios considerables y continuó bajo la dirección de las misiones extranjeras, que seguían siendo las que tomaban las decisiones, dirigían las escuelas y ayudaban económicamente a las congregaciones, con ayuda de los dirigentes nacionales.

El protestantismo en el estado no había sido un grupo religioso homogéneo entre sí, sobre todo por cuestiones doctrinales como el bautismo de los infantes y el servicio de los muertos, lo cual provocó confrontaciones reflejadas en la prensa confesional de las tres denominaciones. ${ }^{4}$ Las diferencias doctrinales y la forma de llevar a cabo sus ritos y ceremonias influyeron al momento de tomar acuerdos conjuntos puesto que, ante la necesidad de cooperación para idear estrategias misioneras, los bautistas tuvieron conflictos con sus homónimas por el monopolio del campo religioso al sur del estado, en Tierra Caliente. ${ }^{5}$

su statu quo, participar del reparto agrario y fortalecer su anticlericalismo. Por otra parte, por ser un deber cristiano respetar a las autoridades constituidas. Mendoza, "Protestantismo liberal", "Política religiosa en Michoacán".

${ }^{4}$ Presbiterianos: El Faro. Metodistas: El Evangelista Mexicano y El Abogado Cristiano Ilustrado. Bautistas: El Atalaya Bantista y El Bautista.

${ }^{5}$ Como ya lo hemos argumentado, el protestantismo en Michoacán fue heterogéneo y poco unido; en 1909 hubo una disputa entre presbiterianos y bautistas por el monopolio de la región de Tierra Caliente, generada por la doctrina del bautismo (los presbiterianos practicaban el bautismo por rociamiento y los bautistas por inmersión). El misionero Félix C. Gómez mencionaba que había una "gran división por la intervención de los bautistas en nuestro campo de trabajo pues ellos vienen a enseñar doctrinas particulares de inmersión [...] se llevó casi a toda la congregación al arroyo donde fueron sumergidos, solo dos jefes de familia nos han quedado fieles". La presencia presbiteriana disminuyó notablemente en esta región debido a que los bautistas se inmiscuían en las congregaciones presbiterianas para convertir a los fieles presbiterianos a su doctrina religiosa. "Insectos venenosos", El Faro (1ํㅗ sep. 1887), p. 135. "Viaje 
Estas discrepancias ocasionaron, en el ámbito nacional, que los bautistas rechazaran las alianzas y estrategias de organización, propuestas por las demás denominaciones para hacer frente a la Constitución de 1917. En varias reuniones celebradas para recomendar algunas políticas sistemáticas para la supervivencia misionera estadounidense, en las cuales no participó la misión bautista, se decidió que en 1919 los presbiterianos del norte y los metodistas del sur salieran del estado y entregaran sus templos y escuelas a la misión presbiteriana del sur. Los bautistas del sur, por su parte, siguieron conservando sus congregaciones. ${ }^{6}$

Este reacomodo forzado, puesto que fue una decisión tomada por las misiones madre de Estados Unidos, sin la aprobación de los pastores mexicanos, coincidió con el gobierno de Francisco J. Múgica, quien al aplicar la política anticlerical en Michoacán, de manera inevitable incluyó a las denominaciones protestantes representadas por los bautistas y presbiterianos del sur, que se encontraban en pleno reajuste estratégico dentro de la sociedad. Aunque no lo abordamos en esta investigación, la situación que se suscitó en 1919 evidenció un protestantismo fragmentado y una conciencia nacionalista de las congregaciones mexicanas, que se venía gestando desde el inicio de la revuelta armada.

\section{ANTICLERICALISMO Y RESURGIMIENTO DE LA INTOLERANCIA}

RELIGIOSA EN EL GOBIERNO DE FRANCISCO J. MÚGICA

Múgica llevó a cabo una política de anticlericalismo abierta y aplicó su programa radical en materia educativa, agraria y laboral, lo que le granjeó el rechazo del clero, que no le perdonaba haber impulsado los artículos anticlericales de la Constitución.?

evangelista" (1ํabr. 1900), p. 51. "El evangelio en Tierra Caliente” (30 abr. 1909), p. 280.

${ }^{6}$ AHIMMAR, Annual report of the minutes of the Central Conference of the Mexican Mission of the Methodist Church of Southern, años de 1916-1919.

7 Sánchez Díaz, “Los elementos y las acciones”, p. 110. 
Temerosos de que la relativa calma de la que habían gozado durante el gobierno de Ortiz Rubio terminara y que hubiera una escalada de nuevas restricciones, el clero y los fieles católicos iniciaron una campaña de confrontación contra Múgica, que incluyó, además de procesiones y desacatos, nuevos brotes de intolerancia religiosa contra los protestantes de Morelia. El 12 de octubre de 1920, llevaron a cabo una peregrinación conformada por una muchedumbre de fieles católicos, que contó con más de 4000 individuos, quienes a su paso iban repartiendo volantes en los que se juraba adhesión al clero católico y se condenaba cualquier apego de los fieles en favor de los protestantes presbiterianos y bautistas de la capital. ${ }^{8}$

Múgica le hizo saber al presidente interino, Adolfo de la Huerta: "se ha hecho todo lo posible para evitar la procesión de manera pacífica y se ha suplicado al arzobispo [Leopoldo Ruiz y Flores] para que evite el acto de culto externo. Pero nada se consiguió”. Además, le comunicó que ante la situación había consignado a los involucrados ante la justicia federal para que actuara con toda energía. El comunicado dejó ver una especie de molestia por tener que involucrar a la federación en problemas que únicamente atañían al gobierno estatal, puesto que Múgica señalaba que "a pesar de lo anómalo de la situación [...] se lo digo para que sepa que se hará cumplir la ley [...] aunque por el delito de que se trata lo puede perseguir el estado como auxiliar de los poderes de la unión, ya que se trata de una infracción constitucional". ${ }^{9}$

\footnotetext{
8 AHPEM, Secretaría de Gobierno, Gobernación, Asuntos Religiosos, c. 2, exp. 34, ff. 1-3, El gobernador constitucional Francisco J. Múgica al Presidente de la República sobre peregrinación efectuada el día 12 de octubre de 1920 contra los protestantes (13 oct. 1920).

9 AHPEM, Secretaría de Gobierno, Gobernación, Asuntos Religiosos, c. 2, exp. 34, ff. 1-3, El gobernador constitucional Francisco J. Múgica al Presidente de la República sobre peregrinación efectuada el día 12 de octubre de 1920 contra los protestantes (13 oct. 1920).
} 
Ese mismo día y antes de llevarse a cabo dicha manifestación, el gobernador había girado instrucciones al teniente coronel y comisario general de policía para que previniera a los líderes de la manifestación no llevar a cabo los números marcados con las letras $\mathrm{E}$ (sobre que se harían procesiones dirigidas por las agrupaciones católicas y obreras) y $\mathrm{H}$ (sobre que habría una quema de fuegos artificiales en la calzada de Guadalupe y un repique de campanas al finalizar los festejos), porque a todas luces constituían actos de culto externo según el artículo $24^{\circ}$ federal. ${ }^{10}$

Atendiendo a las recomendaciones, las autoridades giraron un oficio previniendo a las asociaciones firmantes sobre las implicaciones penales que tendría dicha procesión, pero a pesar de la previsión, la peregrinación, los fuegos artificiales y el repique de campanas se llevaron a cabo. Por esta desobediencia, el día 13 de octubre el gobernador dio las órdenes pertinentes para que se ejecutaran acciones penales contra los responsables. ${ }^{11}$ Esta manifestación católica con tintes marcadamente antiprotestantes es interesante, puesto que es la primera de la que tenemos noticia desde el porfiriato, en que el clero había llevado a cabo lo que en palabras de los periódicos liberales de la época era una "cruzada santa en contra de los infieles" protestantes. Hay que decir también que, como ahora sucedía, las autoridades atendieron de manera oportuna las quejas, sobre todo para proteger a los extranjeros que se encontraban en las congregaciones. ${ }^{12}$

${ }^{10} \mathrm{El}$ artículo $24^{\circ}$ federal garantizaba la libertad de creencias y de culto de todo individuo únicamente dentro de los templos o domicilios, siempre que no constituyeran un delito. El artículo $1^{\circ}$ de la Constitución de Michoacán corroboraba las garantías ofrecidas en el artículo $24^{\circ}$ federal. Nueva Edición del Diario de Debates, p. 992.

${ }^{11}$ AHPEM, Secretaría de Gobierno, Gobernación, Asuntos Religiosos, c. 2, exp. 34, ff. 1-3, El gobernador constitucional Francisco J. Múgica al presidente de la República sobre peregrinación efectuada el día 12 de octubre de 1920 contra los protestantes (oct. 1920).

${ }_{12}$ Sin título, La Unión Michoacana (3 feb. 1881), pp. 3-4. Sin título, El Explorador (24 ago. 1884), p. 4. Sin título, El Grano de Arena (5 feb. 1886), pp. 1-4. 
Siguiendo con su postura anticlerical, Múgica se negó a devolver las escuelas y curatos al clero de Uruapan, ordenó cerrar el Colegio Teresiano de Morelia e intentó trasladar la Escuela Normal de Morelia al edificio teresiano. Para contrarrestar la fundación del Seminario Diocesano en el novel obispado de Tacámbaro, fundó la Escuela Normal Rural de Tacámbaro y determinó que fuera mixta. Además, clausuró la Escuela de Jurisprudencia porque estaba dirigida por sacerdotes y estudiaban en ella reconocidos católicos. ${ }^{13}$

El 8 de mayo de 1921, con motivo del aniversario de los "mártires de Chicago", algunos miembros del Partido Socialista y seguidores mugiquistas colocaron una bandera rojinegra en una de las torres de la catedral de Morelia. Esto ocasionó un forcejeo que culminó en el "ultraje" contra una imagen religiosa y el apaleamiento del cura. Tres días después las mujeres católicas efectuaron una manifestación protestando por los hechos ocurridos que partió del templo de San Diego y se extendió por toda la avenida Francisco y Madero, pero al llegar a la Catedral fueron detenidas por las autoridades acusándolas de exhibir un estandarte religioso. Para este momento los ánimos de la población católica se encontraban exaltados, lo que ocasionó que el día 12 los católicos en masa recorrieran las calles a pesar de que las autoridades les habían negado el permiso por temor a una confrontación. En esta manifestación el clero convocó a varias asociaciones religiosas, entre ellas la Asociación Nacional de Padres de Familia, la Acción Católica de la Juventud Mexicana y varios sindicatos católicos, quienes reunieron a una multitud de aproximadamente 7000 personas. Para calmar los ánimos y evitar que la manifestación se efectuara, la Secretaría de Gobierno pidió al jefe de operaciones militares mandar un

Sobre la intolerancia religiosa contra los protestantes en Michoacán entre 1876 y 1901, véase Mendoza, "Protestantismo liberal".

${ }_{13}$ Meyer, La Cristiada, pp. 114-124. Sánchez Rodríguez, Grupos de poder, pp. 141-145. 
contingente y giró órdenes al inspector general de policía para disolverla. Sin embargo, el enfrentamiento sobrevino, resultando en el asesinato del líder agrarista Isaac Arriaga y del jefe de la policía especial José Martínez. Del lado de los católicos hubo diez hombres muertos. Ante los hechos y presionado por las protestas de varias localidades, Obregón envió a José I. Lugo, secretario de Gobernación, para que se hiciera cargo de la situación en Morelia. ${ }^{14}$

Lejos de menguar, los problemas con el clero se agudizaron con motivo de que en junio siguiente las autoridades hicieron algunas detenciones y enjuiciaron a varios miembros del Partido Católico de la Juventud Mexicana, bajo el cargo de haber violado las leyes en materia de culto público al portar en las calles los distintivos que los acreditaban como miembros de dicha sociedad, entre ellos una imagen en forma de cruz en el centro. ${ }^{15}$ Debido a la actitud anticlerical de Múgica, los sectores católicos lo tacharon de "comecuras excarrancista, partidario de jacobinos rabiosos”. Decían además que él y sus correligionarios eran “alimañas ponzoñosas”, inculpándolo de haber defraudado al erario de Tabasco y de tener relación con anarquistas y bolcheviques. ${ }^{16}$

Las denuncias de los católicos contra los protestantes también se multiplicaron, sobre todo contra los presbiterianos de Zitácuaro. En una ocasión, el arzobispo Ruiz y Flores fue amenazado por los presbiterianos liberales del lugar durante un conato de violencia suscitado por su llegada a la ciudad, que culminó en su huida al monte. Sin duda este acto fue un ataque a la dignidad del arzobispo, quien en mayo de 1920 advirtió a los fieles de su arquidiócesis sobre la inmoralidad que suponía el protestantismo como una forma de imperialismo yanqui y su relación con las reformas revolucionarias, sobre todo aquellas que tenían que

\footnotetext{
${ }^{14}$ Meyer, La Cristiada, pp. 114-117.

15 AHPEM, Secretaría de Gobierno, Gobernación, Asuntos Religiosos, c. 2, exp. 35, ff. 1-46 (1921).

16 Sánchez Díaz, “Los elementos y las acciones”, pp. 111-115.
} 
ver con el reparto agrario. Tachó a los presbiterianos de llevar a cabo una propaganda herética cuyo propósito era dividir a la nación mexicana. ${ }^{17}$

El temor que mostraba el clero católico ante el crecimiento del protestantismo no estaba tan infundado, pues lejos de que el conflicto revolucionario hubiera minado la presencia de los protestantes en el estado, éstos fortalecieron sus congregaciones en el contexto del conflicto religioso.

EL DESARROLLO DEL PROTESTANTISMO, SUS TEMPLOS, ESCUELAS Y HOSPITALES

A pesar de los conflictos religiosos entre el clero y las autoridades, las iglesias protestantes siguieron llevando una vida activa. Las misiones bautista y presbiteriana continuaron haciendo propaganda religiosa y sus templos permanecieron abiertos al culto público aunque con algunas muestras de intolerancia de parte de varios sectores católicos, como el caso del conato de violencia contra los bautistas el día 18 de febrero de 1922, en que los fieles católicos "asaltaron el rancho del Durazno propiedad del bautista Rafael González y González, a quien asesinaron”. ${ }^{18}$

Los archivos y documentos no hablan mucho de la política del gobierno hacia las iglesias protestantes, y creemos que ello ocurrió por su actitud acomodaticia ante las autoridades anticlericales en turno, actitud que podemos apreciar desde el porfiriato. A pesar de que Bastian ha señalado que ciertas congregaciones protestantes fueron un espacio desde donde se impulsó un antiporfirismo, que dio paso a una conciencia revolucionaria, ${ }^{19}$ hay que tomar esta afirmación con cautela puesto que esta actitud no fue una postura generalizada dentro del protestantismo. Para

17 Butler, Popular Piety, pp. 185-188.

${ }_{18}$ Treviño, Historia de los trabajos, pp. 252-253.

19 Bastian, Los disidentes, pp. 11-12, 201, 291-292. 
el caso de Michoacán - como ya lo he argumentado en mis investigaciones - , los protestantes no únicamente no fueron antiporfiristas, sino que apoyaron abiertamente las constantes reelecciones de Porfirio Díaz, del gobernador Aristeo Mercado y del prefecto político de Zitácuaro Aurelio Arciniega, formando parte de los clubes reeleccionistas. ${ }^{20}$

¿Por qué motivo parte de la élite más importante que engrosaba las filas del presbiterianismo y que además ocupaba cargos políticos pensaría en salirse del marco general de gran solidez que les brindaba el gobierno porfirista? Habría que decir que si esta élite decidió tomar las armas, lo hizo de manera tardía, después del asesinato de Francisco I. Madero - contra Victoriano Huerta-, con el propósito de defender su statu quo, defender sus localidades, acceder al reparto agrario y reforzar el anticlericalismo. ${ }^{21}$

Cuando en 1914 los presbiterianos incorporados a la brigada Colín tomaron la plaza de Zitácuaro, en el acto cívico y verbena popular organizada por la Junta Liberal para darle la bienvenida a los "colorados de Luis Colín", el encargado de ponerle la banda de honor y de emitir el discurso oficial fue el pastor presbiteriano Ezequiel María Castillo. En su discurso agradeció al general Luis Colín, entre otras cosas, por haberse conducido con respeto hacia la población, sobre todo hacia las propiedades y las

${ }^{20}$ Sin título, El Estado de Michoacán (23 abr. 1889), p. 2. Sin título, La Democracia (6 mar. 1892), p. 2. Sin título, Periódico Oficial de Michoacán (8 ago. 1895), p. 5. "Visita del Sr. Gobernador a Zitácuaro", Periódico Oficial de Michoacán (3 nov. 1895), p. 7. Sin título, Periódico oficial de Michoacán (28 jul. 1904), pp. 3-4. "Ezequiel M. Castillo, a la redacción de El Faro", El Faro (9 jul. 1909), p. 448.

${ }^{21}$ De la misma forma actuaron las congregaciones ubicadas en los corredores de Ciudad Guerrero y la región Tlaxcala-Puebla, que se adhirieron a los revolucionarios para adaptarse a las circunstancias y proveer a sus miembros de una mayor seguridad y beneficio económico, mientras encontraban mecanismos con los cuales sortear el conflicto armado. BALDwin, Protestants and the Mexican Revolution, 1990. 
vidas, “cosa no vulgar en tiempos de Revolución”. Por tal forma de proceder el pueblo de Zitácuaro le rendía honor y gratitud. ${ }^{22}$ Cuando la brigada Colín entraba a alguna localidad, la población los recibía con beneplácito porque respetaban sus vidas y no se dedicaban al pillaje, incluso en algunas ocasiones los ayudaron con parque y pertrechos, como sucedió en Jungapeo. ${ }^{23}$

Los metodistas del sur, que estuvieron en el estado de 1880 a 1919, y los bautistas del sur, tuvieron incluso menos participación en el levantamiento revolucionario. Se mostraron a la expectativa y sin involucrarse en los acontecimientos políticos por dos razones. La primera y más importante fue que, en el caso de los metodistas, la misión estadounidense les hizo saber que debían actuar en completa y absoluta sujeción a la Constitución: "en primera instancia nosotros estamos muy desconcertados y perplejos pero estamos descubriendo que nos queda mucho por hacer como misioneros y que al mismo tiempo debemos ser respetuosos de las actitudes de las nuevas leyes". ${ }^{24}$ En segundo lugar, en las ciudades, tanto las congregaciones metodistas como las bautistas estuvieron formadas por individuos alejados de la política, con un bajo perfil económico, siendo la mayoría de las veces empleados, tortilleras o personas con algún oficio en el que apenas ganaban lo suficiente para vivir y sostener parte del culto, y agricultores e indígenas en las rancherías, imbuidos de un pensamiento de no intervención en los asuntos políticos, por no ser una actitud acorde con los principios cristianos. ${ }^{25} \mathrm{En}$ Morelia, por ejemplo, ni los bautistas ni los metodistas contaron con un instituto de educación superior que preparara a los

22 Teja Andrade, Zitácuaro, pp. 111-112.

${ }^{23}$ Pérez Escutia, La Revolución, pp. 93-95, 116, 128-129.

${ }^{24}$ AHIMMAR, Annual report of the minutes of the Central Conference of the Mexican Mission of the Methodist Church of Southern, 1918, pp. 22, 196. ${ }^{25}$ Esta actitud fue tomada por los metodistas de Jalisco, quienes se mostraron desinteresados o pasivos ante el movimiento revolucionario. Dorantes, "Una asociación protestante”, pp. 61-82. 
jóvenes a tomar conciencia de la realidad política, como sucedió con los metodistas del norte de la zona Puebla-Tlaxcala, quienes se unieron a la Revolución por una conciencia democrática y antireeleccionista impulsada por el Instituto Metodista de Puebla, viendo en la lucha la posibilidad de acceder a puestos políticos y conseguir colmar sus aspiraciones económicas y mejoras sociales. ${ }^{26}$

La diferencia con los presbiterianos, respecto de su participación política y su pensamiento liberal y democrático, radica principalmente en que estas características no fueron el resultado de su nueva religiosidad - aunque la religión calvinista sí reforzó más tarde su postura y pensamiento liberal jacobino-; tenemos que tener presente que cuando el presbiterianismo se difundió en el oriente de la entidad, lo hizo atrayendo a los individuos que de antiguo ya pertenecían a clanes familiares con cierto poder económico y político, además de ser personas con un marcado pensamiento liberal jacobino practicado mucho antes de que llegaran los presbiterianos. A partir de la segunda mitad del siglo xix, los liberales fortalecieron su ideología política al adherirse a una nueva oferta doctrinal que privilegiaba las libertades individuales, pugnaba por la separación de la Iglesia y el Estado y predicaba un anticlericalismo. Si bien, las congregaciones estuvieron compuestas por obrajeros, zapateros, indígenas, carpinteros, rancheros y trabajadores en las haciendas, fue la élite presbiteriana la que se involucró en las decisiones políticas del distrito. ${ }^{27}$

En este contexto de no intervención revolucionaria de parte de bautistas y de apego a la política constitucional y anticlerical de Múgica, de los presbiterianos, es en el que debemos ubicar al protestantismo en Michoacán. Con ello podemos comprender

\footnotetext{
${ }^{26}$ Fuentes BazÁn, “Los estudiantes del Instituto Metodista Mexicano”.

${ }^{27}$ Libro de Registro de la Iglesia Presbiteriana Getsemaní de Zitácuaro, años de 1877-1890. “Viajes misioneros”, El Faro (1ํjul. 1894), p. 102.
} 
de manera más acertada por qué, pese a los inconvenientes causados por las restricciones de las leyes constitucionales en detrimento de las religiosidades, las congregaciones seguían funcionando con regularidad. La respuesta es que no fueron vistas como agentes contrarios a los intereses del gobierno, sino más bien como obedientes a las leyes, además de aliadas de la política anticlerical y agrarista de Múgica. Por ello fue que la década de 1920 significó un repunte en los trabajos de las dos misiones ya que, según las estadísticas oficiales de los censos de población, la matrícula de protestantes pasó de 4349 a 7343 . Es decir, de constituir $0.46 \%$ en 1921 , crecieron a $0.70 \%$ en 1930 . El éxito de este crecimiento se debió a un proselitismo religioso activo, la conveniente sujeción a las leyes en materia de culto público y un contexto político anticlerical que los favoreció, puesto que las autoridades estaban más enfocadas a minar la intervención del clero en los asuntos políticos.

La Iglesia bautista declaró que estaba abriendo nuevos puntos de predicación en las localidades de Etúcuaro y Teremendo, y en las rancherías circunvecinas de San Juan Tumbio, Tiríndaro, Tarejero y Naranja. Además de las localidades de Jicalán, Jucutacato, Ario de Rosales, Lombardía y el Rancho Boluta. Dijo además que sus trabajos continuaban llevándose a cabo de manera normal y sin más contratiempos, bajo la dirección de los predicadores estadounidenses con ayuda de los mexicanos José Ramírez, Adán Fuentes y Miqueas D. Godínez, a pesar de algunos conatos de violencia de parte de bandoleros y ciertos católicos intolerantes. Gracias a las labores de expansión, la misión expuso que la matrícula de sus miembros había crecido. ${ }^{28}$

También hubo cambios favorables para la denominación bautista de Morelia cuando en 1922 la misión estadounidense compró un predio y trasladó el domicilio del templo, en el que estuvo

\footnotetext{
${ }^{28}$ David Montemayor, "Primera Iglesia Bautista de Morelia Michoacán. Un pasado heroico", México, manuscrito inédito, 2006, p. 22.
} 
por más de 30 años, a la construcción ubicada en la manzana 5 del cuartel 4 de la avenida Francisco I. Madero. Esta casa, donde ahora se situó el templo, había pertenecido a Jesús Jaimes Avilés y su esposa Anselma de la Piedra, quienes el 4 de septiembre la vendieron al misionero estadounidense bautista Carlos L. Neal por la cantidad de 13500 pesos. ${ }^{29} \mathrm{La}$ compra del predio por parte de un extranjero que además era protestante fue un claro ejemplo de que los artículos en materia religiosa no fueron aplicados a los evangélicos como debería haber sucedido.

Por lo que respecta a la misión presbiteriana del sur, se había hecho cargo de los antiguos templos metodistas y presbiterianos del norte. En la ciudad de Morelia estaba al frente del templo denominado Iglesia de Salem, antiguo templo metodista, que continuaba abierto al culto público en el número 85 de la calle García Obeso esquina Corregidora, el cual seguía registrado como propiedad del misionero estadounidense metodista Guillermo M. Patterson, quien había comprado la propiedad en $1886 .{ }^{30}$ Durante la gubernatura de Múgica los presbiterianos también extendieron sus trabajos en el resto del estado abriendo nuevas congregaciones bajo la supervisión de misioneros estadounidenses.

Respecto de la política educativa tendiente a eliminar la enseñanza religiosa de los planteles particulares, y a prohibir que profesores protestantes estuvieran al frente de las escuelas, según se estipulaba en los artículos $3^{\circ}$ y $130^{\circ}$ constitucionales, las misiones protestantes lograron dar un impulso considerable a los colegios bajo la supervisión de profesores extranjeros. ${ }^{31}$

${ }^{29}$ David Montemayor, "Primera Iglesia Bautista de Morelia Michoacán. Un pasado heroico", México, manuscrito inédito, 2006, p. 13.

${ }^{30}$ Sedesol, Dirección de Bienes Nacionales, Oficina Federal de Hacienda, Templo Presbiteriano de Morelia, ff. 23-26 (mar. 1935), ff. $72-73$ (ago. 1939). Libro Histórico del Sinodo, pp. 118-119.

${ }^{31}$ En la Constitución estatal de 1918 se hizo énfasis en el aspecto educativo por medio de los artículos 137, 138, 139, 140 y 142 - que correspondían al artículo 


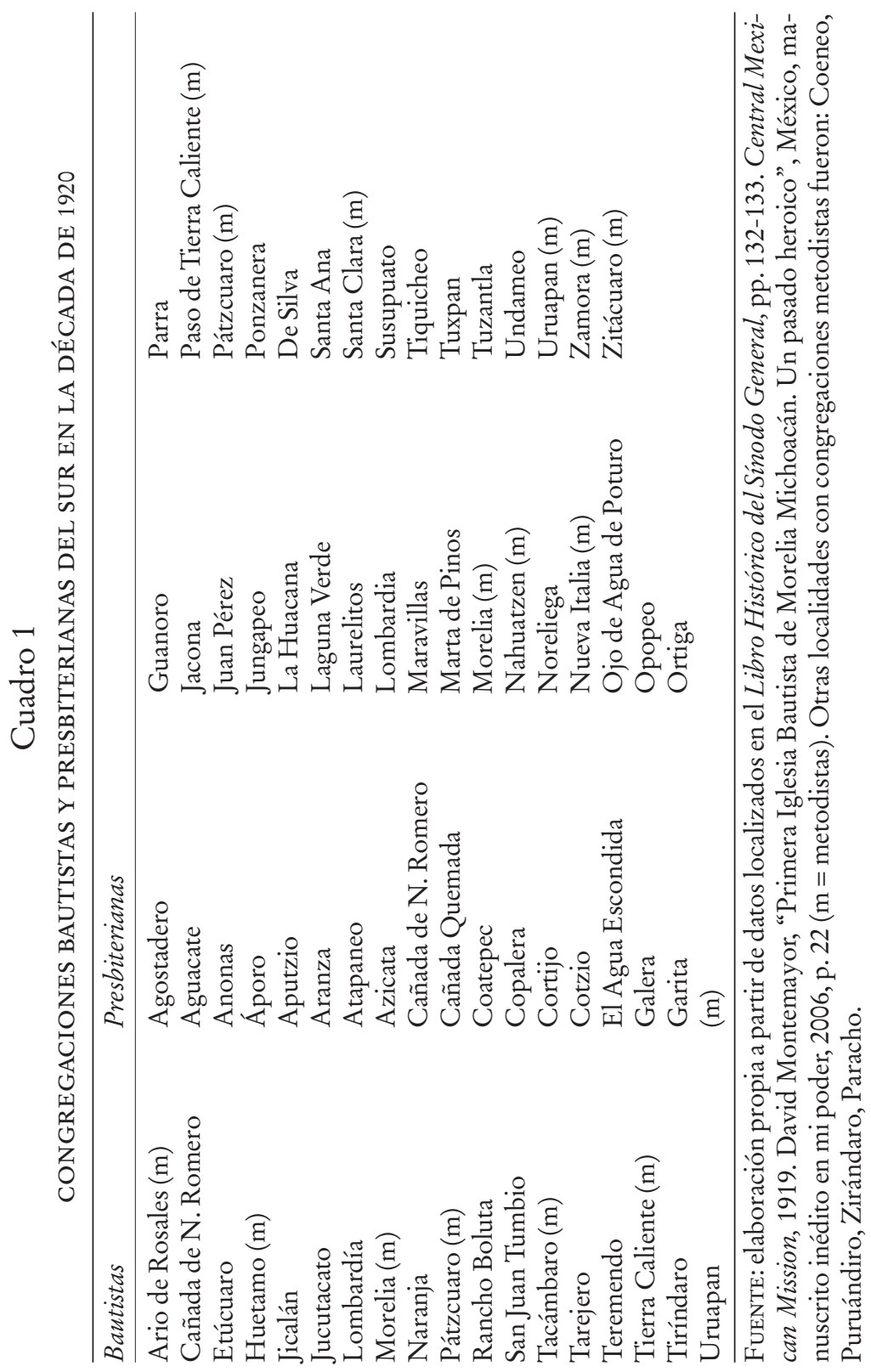


Por lo que toca a la Iglesia bautista, a pesar de que ésta no se había caracterizado por impulsar espacios escolares durante el porfiriato, la misión abrió una escuela en 1923 en la ciudad de Morelia bajo la dirección de la misionera y maestra estadounidense Annie M. Long, quien junto con L. O. Engleman se hicieron cargo del plantel que quedó instituido bajo el nombre de Escuela Progreso. La escuela, que tuvo el carácter de primeras letras, quedó ubicada en uno de los anexos de la calle Francisco I. Madero Oriente con el número 636, donde compartió el espacio con un internado para mujeres y para varones, el cual cerró sus puertas en el año 1926 con motivo del conflicto cristero. ${ }^{32}$

La misión presbiteriana del sur, que en materia de educación se había puesto a la cabeza de las misiones estadounidenses en el estado gracias a la labor hecha por sus homónimos del norte desde 1876, dio un nuevo impulso a sus trabajos en el área educativa. ${ }^{33}$ El reverendo estadounidense Hervey L. Ross y su familia fueron enviados a Zitácuaro en 1920, y para coadyuvar en el trabajo educativo en las escuelas de primeras letras, en abril de 1922 llegaron las misioneras Catarina Gray y Leticia Beatty. Un año más tarde, a Leticia Beatty se le nombró directora de

$3^{\circ}$ federal. En los dos primeros se habló de la obligatoriedad y gratuidad y en el último de la laicidad de la educación pública y privada. La vigilancia sobre las escuelas particulares fue abordada en el 140, y en el 142 se dispuso que ninguna corporación protestante ni sus ministros podrían establecer o dirigir escuelas primarias. El tema sobre la restricción de los maestros protestantes en las escuelas fue tratado en el 143 -correspondiente al artículo 130 federaldonde se les negó la revalidación de sus títulos de profesores obtenidos en las normales protestantes. "Constitución Política del Estado libre y soberano de Michoacán de Ocampo”, Periódico Oficial (mar. 1918).

32 David Montemayor, "Primera Iglesia Bautista de Morelia Michoacán. Un pasado heroico", México, manuscrito inédito, 2006, p. 23.

${ }_{33}$ Mendoza, "Instrucción cívica y liberal”, pp. 53-92. 
la escuela Leona Vicario. ${ }^{34}$ Este plantel quedó formalmente incorporado a la educación oficial del estado hasta que cerró sus puertas en $1929 .{ }^{35} \mathrm{La}$ escuela estuvo apoyada por un cuerpo de profesoras nacionales egresadas de las escuelas presbiterianas entre las que destacaron por su trayectoria Eufemia Manjarrez, Raquel Reyna y Esperanza Gallegos. ${ }^{36}$

${ }^{34}$ La escuela abrió sus puertas en 1901, suspendió sus labores en 1905 por problemas económicos, y con la ayuda de la misión, en 1910 el establecimiento fue reabierto. En esta segunda etapa se renovaron los planes de estudio, se amplió la planta de profesoras y le fue cambiado el nombre por "Centenarista Leona Vicario". Las labores continuaron hasta 1913, cuando la escuela suspendió sus actividades para posteriormente reabrir por otros periodos de tiempo. En 1929 se convirtió en un internado para señoritas atendido por la Unión Femenil y dirigido por Juana R. de Gómez, con la colaboración de Virginia A. de Álvarez, María Gómez, Eleuteria Zamano y la misionera estadounidense Catalina Gray. Ocupó parte del edificio donde estaba la escuela secundaria para varones Melchor Ocampo (que había reemplazado a la escuela de varones Graybill), en un espacio donado por la misión estadounidense. Los dos internados fueron subsidiados por la misión y los padres de familia, quienes aportaron cada uno 50\% del total de gastos. DuARTE, Zitácuaro, pp. 212-263. "La misión evangélica de la Heroica Zitácuaro", Laurel y Olivo (27 oct. 1901), p. 4. Libro Histórico del Sínodo, p. 145.

${ }^{35}$ La misionera Leticia Beatty se dedicó en adelante a la enseñanza dominical en varias ciudades, incluida Pátzcuaro, al lado de los profesores que ya no pudieron continuar con la labor educativa en las escuelas de primeras letras. VÁzQuez, Los que sembraron, p. 37.

36 1872-1972 Centenario: Iglesia Nacional Presbiteriana, pp. 156-159. Libro Histórico del Sínodo, p. 119. Libro conmemorativo de las bodas de diamante de la Iglesia presbiteriana, pp. 74-75. VÁzQuez, Los que sembraron, p. 57. 


\section{Cuadro 2}

ESCUELAS PROTESTANTES ENTRE 1920 Y 1924

\begin{tabular}{lclll}
\hline Lugar & Número & Nombre & Denominación & Carácter \\
\hline El Aguacate & 1 & Presbiteriana & Mixto & \\
La libertad & 1 & Presbiteriana & Mixto & \\
Manga de Clavo & 1 & Industrial Graybill & presbiteriana & Mixto \\
Morelia & 1 & Presbiteriana & Niñas & \\
Nahuatzen & 1 & Presbiteriana & Mixto & \\
Zitácuaro & 1 & Centenarista Leona Vicario & Presbiteriana & Niñas \\
Zitácuaro & 1 & Melchor Ocampo & Presbiteriana & Varones \\
Morelia & 1 & Escuela Progreso & Bautista & Niñas \\
Morelia & 1 & Internado & Bautista & Mixto \\
\hline
\end{tabular}

FuENTE: elaboración propia a partir de datos localizados en AHIMMAR, Annual report of the minutes of the Central Conference of the Mexican Mission of the Methodist Church of Southern, 1919. Centenario de la Iglesia Nacional Presbiteriana. David Montemayor, "Primera Iglesia Bautista de Morelia Michoacán. Un pasado heroico”, México, manuscrito inédito, 2006. Sobre el programa educativo dentro de las escuelas presbiterianas véase Mendoza, "Instrucción cívica y liberal".

En consonancia con el pensamiento revolucionario de incluir a los campesinos analfabetas en la dinámica nacional, inculcar en ellos los beneficios de la civilización y emanciparlos de la tutela de la religión católica, los presbiterianos trataron de fortalecer la educación rural durante el gobierno de Sidronio Sánchez Pineda. Este ideal presbiteriano agrarista se basaba en el pensamiento del presbiteriano Moisés Sáenz, quien vio en la educación de los indígenas el medio ideal para lograr su integración a la vida nacional. Para desarrollar su pensamiento educativo, Sáenz se basó en la pedagogía de John Dewey por su sentido democrático liberal, integrista y cultural. Esto era significativo porque se acopló al programa revolucionario que buscaba integrar a los campesinos a la dinámica nacional por medio de la educación. Si bien creyó que una reforma agraria era necesaria, Sáenz fue fiel partidario de que de nada serviría si el campesinado no sabía aprovechar las técnicas para trabajar la tierra y la única forma 
de hacerlo era por medio de las escuelas rurales, en las que se implementaron proyectos prácticos como la cría de animales y las diversas formas de cultivo, además de las clases teóricas en los salones de clases. ${ }^{37}$

La misión presbiteriana ya había tratado de poner en práctica el proyecto escolar agrícola e industrial en Montemorelos, Nuevo León, en donde fundaron una escuela a la cual se le puso por nombre Escuela Industrial Graybill. El plantel abrió sus puertas en 1911 en un predio con una extensión de 25 ha, donde se enseñaba a los jóvenes a sembrar maíz, avena, frijol, camote y papa, entre otros productos. En la escuela había talleres con máquinas de vapor para los jóvenes internos que venían de varias denominaciones ubicadas en otros estados y que llegaban con la intención de "instruirse y aprender agricultura científica, oficios, comercio y ministerio". La escuela fue cerrada por causa de la Revolución; sin embargo, el proyecto siguió en pie esperando nuevos tiempos. ${ }^{38}$

Más tarde, en el Congreso Interdenominacional de Cooperación, celebrado en abril de 1919, se dejó sentir con fuerza la decisión de los presbiterianos de abrir escuelas rurales e industriales. Al hablar de la obra educativa de la Iglesia evangélica en México, se recomendó "que se establezcan en distintos puntos de la República y sostenidas por cada denominación [...] escuelas industriales y de agricultura" con el objetivo de fomentar las industrias y la especialidad agrícola, "tan necesaria en estos tiempos de reconstrucción nacional en los que juega un papel tan importante el problema agrario". La recomendación específica de la Comisión fue establecer grandes escuelas agrícolas en Michoacán, además de en otros estados, solventadas por la

37 BRitTon, “Moisés Sáenz”, pp. 77-97.

${ }^{38}$ VÁzQuez, Los que sembraron, pp. 56-58, 216. Centenario de la Iglesia Nacional Presbiteriana, pp. 156-157. Libro conmemorativo de las bodas de diamante de la Iglesia presbiteriana, p. 107. "Otros granitos”, El Faro (17 nov. 1911), pp. 732-733; "Escuela Industrial Graybill” (26 feb. 1912), p. 267. 
misión presbiteriana del sur. Atendiendo a la recomendación, en 1919 el presbiteriano y constitucionalista Saúl Vaca Gallegos trató de fundar una escuela agrícola rural, la cual se sostendría con recursos que llegaron de la misión. ${ }^{39}$

Debido al reacomodo del campo religioso en 1919, el proyecto se pospuso hasta que tomaran posesión del campo los presbiterianos del sur. Una vez que esto sucedió, en 1923 y bajo el mismo nombre, el proyecto de escuela rural fue retomado e implantado en Manga de Clavo. El plantel fue dirigido por el misionero extranjero Rufus Clagg Morrow, además de otros profesores presbiterianos nacionales. La escuela se desarrolló como un plantel industrial agrícola donde se dio instrucción práctica a los hijos de los congregantes presbiterianos, en un afán de educarlos para trabajar la tierra por la cual convenientemente estaban luchando por medio del reparto ejidal. En el plantel de Manga de Clavo, el misionero Morrow perfeccionó el sistema de educación agraria que consistió en clases dentro de las aulas y clases prácticas enfocadas a la labor agrícola en el campo, donde los estudiantes pasaban la mayor parte del tiempo. El sistema educativo agrario fue pensado para inculcar en los alumnos el cultivo de la tierra mediante las técnicas agrícolas más recientes, cuyo fin era sacar el mayor provecho de los productos agrícolas. Para poder echar a andar el proyecto, los presbiterianos compraron varias extensiones de tierra que sirvieron para el trabajo práctico de los alumnos. El proyecto escolar agrícola se fortaleció cuando se decidió anexar una escuela de artes y oficios. ${ }^{40}$

La escuela industrial funcionaba gracias al pago de colegiaturas de los internos, que no excedían los 20 pesos al mes. Dicha colegiatura incluía, además del pago de los profesores y el mantenimiento de la escuela, la asistencia y el lavado de ropa de los alumnos. A

39 "El Congreso Interdenominacional de Cooperación. Sus acuerdos acerca de la obra educacional”, El Abogado Cristiano (3 abr. 1919), pp. 212-213.

40 VÁzquez, Los que sembraron, pp. 56-58, 216. 
los estudiantes que no pudieran pagar las colegiaturas, la escuela se encargó de hacer un convenio con sus familias para buscar la manera en que pudieran solventar los gastos. Además, el establecimiento estuvo incorporado a la educación pública del estado hasta que fue clausurado en $1924 .{ }^{41} \mathrm{La}$ importancia de este sistema educativo demuestra cómo contribuyeron los presbiterianos en la difusión de una pedagogía que trataba de integrar a los campesinos al proyecto de nación, fortaleciendo en ellos el amor por la tierra y a su vez alentándolos para obtenerla por medio del reparto agrario.

Una de las profesoras que impulsaron la pedagogía agrarista en Zitácuaro fue la maestra rural María del Refugio García, quien era militante del grupo mugiquista y directora de debates de la Agrupación de Socialistas Michoacanos residentes en el Distrito Federal. Como inspectora escolar en la zona de Zitácuaro, ${ }^{42}$ y apoyada por la maestra presbiteriana Evangelina Rodríguez, Refugio García trató de impulsar la educación cívica y agrarista. ${ }^{43}$ El hecho de contar con el favor de Múgica y de apoyarse en las mujeres presbiterianas que contaban con una larga trayectoria en materia de educación cívica impartida en los colegios de la misión, permitió a Refugio García lograr la apertura de escuelas como la que se fundó en el rancho El Aguacate en junio de 1923, donde los indígenas, además de cultivar las milpas, aprendieron a fabricar objetos de tule y fibra de maguey que posteriormente comercializaban. ${ }^{44}$ El rancho, ubicado en el municipio de Tuxpan, era propiedad de los presbiterianos Antonio y Guadalupe Vaca. En 1878 se unieron al presbiterianismo y construyeron, en 1883, además de un templo, una escuela para los hijos de sus trabajadores, la cual era atendida por Nicanor Gómez. ${ }^{45}$

\footnotetext{
41 VÁzQuez, Los que sembraron, pp. 56-57.

42 Oikión, Los hombres del poder, p. 87.

43 Sobre la pedagogía cívica y liberal de las escuelas presbiterianas véase MENDOZA, “Instrucción cívica y liberal”, pp. 53-92.

44 Butler, Popular Piety, pp. 113-147.

45 VÁzQuez, Los que sembraron, p. 227.
} 
El apoyo de la profesora presbiteriana Evangelina Rodríguez fue fundamental para llevar a cabo la labor de Refugio García y en general para el proyecto educativo de Múgica, con quien cultivó una estrecha amistad. Hija del hacendado José Inés Rodríguez, de Jungapeo, concluyó sus estudios de primaria en la escuela Leona Vicario de Zitácuaro, para después graduarse como profesora en la Normal Presbiteriana Anglo-Mexicana de Coyoacán (1915-1919), dirigida por el misionero Guillermo E. Vanderbilt. A su regreso se incorporó a las escuelas de Zitácuaro y desarrolló una ardua labor como maestra rural (1923). Por su desempeño en el área de educación fue nombrada inspectora de educación de la zona de Zitácuaro en $1925 .{ }^{46} \mathrm{Su}$ actividad en el área educativa y sus lazos con Múgica hicieron posible que Evangelina fuera considerada un apoyo al proyecto de escuela agrarista.

Una novedad en el presbiterianismo en el estado fue la creación de un hospital en la ciudad de Morelia, que con el nombre de Sanatorio La Luz abrió sus puertas el 21 de septiembre de 1921 en la casa del Dr. L. J. Coppedge, ubicada en la calzada Fray Antonio de San Miguel; había sido casa particular y clínica del exgobernador del estado, Dr. Miguel Silva. Su labor no fue únicamente la de brindar un espacio de salud a la población, sino también un espacio de educación dedicado a impartir la carrera de enfermería en los anexos del hospital. La escuela de enfermería se inauguró en 1929. La propiedad fue comprada a nombre de la misión presbiteriana del sur por los misioneros H. L. Ross, W. A. Ross y Santiago Shelby, por la cantidad de 12000 dólares, y quedó registrada con el nombre de Compañía Educadora La Luz. Posteriormente, el sanatorio se trasladó a la calle General Bravo, en el número 50 de la colonia Chapultepec Sur, bajo la

46 "Evangelina Rodríguez Carbajal”, http://www.periodicoeldespertar.com. Consultado el 10 de octubre de 2016. 
dirección de los misioneros presbiterianos Coppedge, Annie E. Dysart, Tattye Southerland y Santiago O. Shelby. ${ }^{47}$

\section{LOS PRESBITERIANOS ANTE EL REPARTO AGRARIO}

A la par del desarrollo protestante se recrudecieron los enfrentamientos entre el clero y las autoridades del estado suscitados por la política agraria, educativa y del trabajo, lo que ocasionó serios inconvenientes a Múgica. Mientras que los hacendados respondieron a la política agrarista con la creación de las llamadas "guardias blancas" para amedrentar a los pobladores y que no recibieran tierras, y en respuesta a la promulgación de la Ley del Trabajo fundaron el Sindicato de Propietarios del Estado de Michoacán, el clero realizó su parte fundando asociaciones católicas y predicando a los fieles la inconveniencia del reparto agrario haciéndolo ver como un robo a los hacendados, lo que ocasionó algunos enfrentamientos. ${ }^{48}$

Para evitar que el clero y terratenientes siguieran obstaculizando el reparto agrario, Múgica reorganizó a las "defensas civiles" constituidas a partir de los propios elementos de las comunidades, a las que armó y les dio atribuciones de policías. Las defensas se hicieron necesarias por cuanto que el clero católico, alentado por una pastoral del arzobispo Monseñor Ruiz y Flores, dictada en 1920 - en la cual acusó a los indígenas de ladrones porque "han ido a cosechar las tierras que ni siquiera habían sembrado" -, provocó algunos motines como el que sucedió en Turicato. ${ }^{49}$

\footnotetext{
47 Libro Histórico del Sínodo, pp. 118-119. Libro conmemorativo de las bodas de diamante de la Iglesia presbiteriana, pp. 93-112. VÁzQuEz, Los que sembraron, pp. 56-58. "Iglesia Nacional Presbiteriana de México."

${ }^{48}$ Hacia 1922 hubo enfrentamientos en las localidades de Contepec, El Caracol, Acahuato, Tepalcatepec, Uruapan, Tacámbaro, Turicato y Panindícuaro. Meyer, La Cristiada, p. 120.

49 Sánchez Díaz, "Los elementos y las acciones”, p. 113.
} 
Sobre los hechos de Turicato, el 30 de enero de 1922 los miembros de la defensa civil del lugar denunciaron la llegada de dos misioneros católicos que habían sido solicitados por el obispo de Tacámbaro, Leopoldo Lara y Torres - quien además se caracterizaba por su actitud radical contra el protestantismo en el estado-, para que lo ayudaran en las confirmaciones de los fieles. Una vez que arribaron comenzaron una serie de predicaciones en las cuales recomendaron a los feligreses no respetar la Ley del Trabajo ni la Ley Agraria, "que es lícito matar al que se trate de apoderar de lo ajeno, que no hay que mandar a los hijos a las escuelas laicas porque les quitan la religión de Cristo [...] invitan a los niños y hombres a pelear para defender la religión católica y en general que no respeten las leyes porque el gobierno es un bandido". No debían aceptar las tierras que les daba el gobierno porque el acto sería considerado por la Iglesia como un robo al prójimo. Asimismo, el obispo Leopoldo Lara también había predicado en el sentido de que se debía cuidar que el gobierno no llevara a efecto el propósito, incluso a costa de "la última gota de sangre".$^{50}$

En Zitácuaro el problema agrario se evidenció a partir de la formación de una élite política que, aprovechando las reformas liberales, había tomado posesión de las tierras de los eclesiásticos. Hacia 1920, este grupo fue el que controló el poder, focalizó los recursos económicos y ocupó algunas tierras indígenas mediante la Junta Patriótica Liberal Benito Juárez, liderada por el presbiteriano Enedino Colín. ${ }^{51}$ A pesar de que se agruparon en torno a ella presbiterianos exrevolucionarios, pastores, médicos

\footnotetext{
${ }^{50}$ AHPEM, Secretaría de Gobierno, Gobernación, Asuntos Religiosos, c. 3, exp. 36, Turicato, los Jefes de defensas de este lugar dan cuenta con la propaganda que trata de hacer el obispo Leopoldo Lara y sus habitantes (enero 1922). ${ }^{51}$ La Junta se fundó el 30 de septiembre de 1895. En las elecciones de 1911 respaldó la candidatura del Dr. Miguel Silva, iniciando los trabajos de propaganda en el periódico La Idea. La familia Colín detentó el poder de la Junta durante varias décadas. Sin título, La Idea (20 oct. 1912), p. 1.
} 
y maestros, entre ellos Saúl Vaca Gallegos, Moisés Alvarado, Neftalí Novo Cejudo, Ezequiel María Castillo y Enrique Reyna, la actitud e ideología de éstos ocasionó serias divisiones en la Junta, sobre todo por sus ideas radicales en favor del reparto agrario y por su apoyo a Francisco J. Múgica.

Estos personajes presbiterianos, de pensamiento jacobino y de una importante trayectoria política dentro de la sociedad zitacuarense, delinearon su actuar político a partir del porfiriato, así como también durante la lucha armada y constitucionalista, siendo lo que Butler llama "revolucionarios de pueblo". Saúl Vaca Gallegos perteneció a una familia de rancheros oriunda de Jungapeo y fue alumno del Seminario Teológico Presbiteriano para varones de Tlalpan en la ciudad de México (1892 y 1893) en donde se graduó como pastor y obtuvo el título de maestro, ejerciendo esos títulos en las congregaciones y escuelas de Jungapeo. Ocupó el cargo de regidor del Ayuntamiento de Zitácuaro (1897) y fue candidato suplente al ramo penal (1901). Gracias a su pensamiento radical anticlerical, logró que la fiesta religiosa más importante de Zitácuaro, celebrada el 8 de diciembre en favor de la Virgen de los Remedios, se cambiara al 5 de febrero en 1897. Fue lector de Regeneración y peleó contra Huerta alineado a la brigada Colín, donde obtuvo el grado de coronel, haciendo además propaganda por medio del periódico El Vigía (1913). Después de ser constitucionalista se alineó a la Convención, para después simpatizar con la causa villista, lo que lo obligó a salir del estado ante la persecución carrancista. A su regreso se declaró constitucionalista y fue delegado a la Convención de Aguascalientes en representación de Luis Colín, ostentando el grado de general. Gallegos fue conocido como uno de los más importantes capitalistas de Zitácuaro. ${ }^{52}$

52 “Informe anual del Seminario Teológico", El Faro (1ํabril 1893), p. 50; (1 feb. 1894), p. 1. "Establecimiento de la fiesta del 5 de febrero en la $H$. Zitácuaro”, El 93 (24 mar. 1901), pp. 7-8. "Crónica de la Reunión del Presbiterio de la Ciudad de México”, El Faro (17 dic. 1909), p. 811. Teja Andrade, 
Moisés Alvarado fue maestro rural y pastor presbiteriano de las congregaciones de Zitácuaro. Después de ser maderista lucho al lado de los constitucionalistas, donde obtuvo el grado de mayor. Ezequiel María Castillo, médico de profesión, fue compañero de Saúl Vaca Gallegos y Joaquín Palomino Mendoza en el Seminario Teológico Presbiteriano de la Ciudad de México. Fue profesor y pastor de las congregaciones y escuelas de Zitácuaro. Mostró amplia simpatía por la política del prefecto porfirista Aurelio Arciniega, tomando la palabra en las tribunas para expresarle su agradecimiento en nombre de los presbiterianos. Colaboró con la misionera Blanche B. Bonine y el reverendo estadounidense $\mathrm{H}$. A. Phillips en la organización de las congregaciones y de las escuelas de Zitácuaro y de la hacienda de El Caracol (1912). Tomó las armas contra Huerta e hizo propaganda al lado de Saúl Vaca por medio del periódico El Vigía. Fue encargado del ramo de instrucción (1913) y colaboró en la creación de sociedades presbiterianas para fortalecer su doctrina e impulsar la temperancia antialcohólica entre la población. ${ }^{53}$

Enrique Reyna Ruiz, anciano presbiteriano de Zitácuaro fue cofundador del Presbiterio de la Ciudad de México, en donde trató de impulsar la autonomía económica de las congregaciones de Zitácuaro respecto de las misiones estadounidenses (1885). Se adhirió, al lado del pastor Felipe Pastrana, a la Junta Electoral de Morelia para apoyar la reelección del gobernador Mariano Jiménez (1887). Al lado de otros presbiterianos, se incorporó al

Zitácuaro, p. 110. "Crónicas y debates de las sesiones de la Soberana Convención Revolucionaria”.

53 “Informe anual del Seminario Teológico", El Faro (1aa. 1893), p. 50; (15 mayo 1899), p. 80; (1ํene. 1900), p. 8; (15 ene. 1900), p. 16. "Convención de Patámbaro" (1ooct. 1902), p. 146. "Ezequiel M. Castillo, a la redacción de El Faro" (9 jul. 1909), p. 448; (18 ago. 1911), p. 519; (16 ago. 1912), pp. 735-737; (16 mayo 1913), p. 293. Teja Andrade, Zitácuaro, p. 110. 
Club Democracia Vigilante de Zitácuaro para asistir al congreso liberal de San Luis (1901).54

Finalmente, Neftalí Novo Cejudo, oriundo de Tuxpan, egresó del Seminario Presbiteriano de Tlalpan, donde se recibió de pastor y maestro (1905). Fue pastor de varias congregaciones de Zitácuaro y maestro en las escuelas presbiterianas de primeras letras de Áporo, Agostadero, Patámbaro y Zitácuaro. Fue un activo propagador de las ideas calvinistas al lado de su hermana Julia Cejudo, profesora egresada de la Escuela Normal Presbiteriana para Señoritas. ${ }^{55} \mathrm{Al}$ igual que como lo hicieron otros presbiterianos, después del asesinato de Francisco I. Madero Neftalí Cejudo apoyó la causa constitucionalista y se adhirió a las fuerzas carrancistas alzándose en el distrito de Juárez, en el estado de Morelos, donde obtuvo el grado de coronel. Aunque simpatizó con las ideas zapatistas sobre el reparto de tierras, en 1915 se unió al constitucionalismo organizando las acciones de defensa contra villistas que merodeaban Maravatío y El Oro, logrando en poco tiempo el control del oriente del estado. Apoyó de manera abierta a Francisco J. Múgica y a Plutarco Elías Calles, dos radicales en materia de religión igual que él y con quienes cultivó una estrecha amistad. ${ }^{56}$

Por otra parte, la élite de la Junta se había inclinado hacia una postura política tendiente a no realizar cambios sustanciales en cuanto a tierras. Este grupo, aunque era anticlerical, en materia política coqueteaba con las ideas moderadas de Pascual Ortiz Rubio, a quien apoyaron en su candidatura al gobierno del

\footnotetext{
${ }^{54}$ Sin título, El Estado de Michoacán (23 abr. 1889), p. 2. "Salud a los liberales de San Luis Potosí, El 93 (23 sep. 1900), p. 3. Libro conmemorativo de las bodas de diamante de la Iglesia presbiteriana, pp. 57, 111.

55 "Facultad y Estudiantes del Colegio y Seminario Teológico Presbiteriano de Coyoacán”, El Faro (1º ene. 1905), p. 2; (15 ago. 1905), p. 5; (1º dic. 1908), p. 183; “A los padres de familia" (10 sep. 1885), p. 71; (15 dic. 1893), p. 187; "Notas de Michoacán” (15 ene. 1905), p. 5 y (10 mar. 1911), p. 151. "La Escuela Normal para Señoritas", El Abogado Cristiano Ilustrado (1º dic. 1893), p. 101. ${ }_{56}$ Butler, Popular Piety, p. 98.
} 
estado $^{57}$ quizá como parte de una estrategia para resguardar los intereses de los propietarios de tierras, como Enedino Colín. Por su parte, los liberales radicales y anticlericales, entre los que destacan los presbiterianos Cejudo, Gallegos y Alvarado, decidieron agruparse en torno de las ideas del Partido Socialista Michoacano, que había apoyado la candidatura a gobernador de Francisco J. Múgica.

Impulsados por el reparto agrario, los mugiquistas radicales de Zitácuaro trataron de reorganizar a los campesinos para hacer los reclamos pertinentes y de esta forma recuperar sus tierras perdidas a manos de los hacendados. Sin embargo, encontraron una severa oposición de la élite política integrante de la Junta Patriótica. La animadversión no fue para menos, puesto que Enedino Colín resultaba ser el más perjudicado debido a que, gracias a la herencia de su padre, era el dueño de la hacienda El Espinal cuyo casco se localizaba en Loma Larga y la cual contaba con aproximadamente 1500 ha. También era dueño de algunos predios de importantes dimensiones a las orillas de la ciudad, localizados entre las calles Artillería y José Ma. Coss, y de Av. Revolución a Dr. Emilio García. En una parte de los terrenos tenía huertos de árboles frutales de pera, lima, durazno y aguacate; la otra parte la sembraba con trigo y alfalfa para el ganado. En otras hectáreas, ubicadas en el poniente de la población, cultivaba magueyes de los cuales comercializaba una importante cantidad de pulque. La familia Colín además era arrendataria de tierras y poseedora de algunas fincas, como la de San José del Molino, productora de maíz. ${ }^{58}$

La actitud de los agraristas causó tal malestar en las autoridades de Zitácuaro, que en 1919 el presidente municipal, en contubernio con Enrique Colín, ambos integrantes de la Junta, asesinaron

57 “Delirante entusiasmo en Zitácuaro”, El Pueblo (13 jun. 1917), p. 5.

${ }^{58}$ Guerra, "Hombres y mujeres de Zitácuaro". 
a dos agraristas en el pueblo de Crescencio Morales. ${ }^{59}$ La lucha por recuperar las tierras de manos de los hacendados no era nueva, desde 1906 los pobladores de Tuxpan, de donde era oriunda la familia Cejudo, habían pedido a la Secretaría de Agricultura y Fomento la devolución de su fundo legal que desde 1890 había sido absorbido por las haciendas. En esa ocasión, entre los quejosos se encontraron los presbiterianos Filadelfo Urquiza (hijo de Pablo Urquiza), Areli Colín y Neftalí Novo Cejudo.

En 1920, ante las nuevas elecciones y bajo la dirección de Isaac Arriaga, se iniciaron las campañas electorales en Zitácuaro, lugar en el que se había abierto un centro de operaciones del Partido Socialista. Fue en este momento cuando los radicales presbiterianos, con la firme idea de que la Junta se había convertido en una oligarquía, se alinearon con la agrupación socialista ${ }^{60}$ apoyados por Múgica, quien envió a Zitácuaro a la maestra María del Refugio (Cuca) García y al periodista Jesús Corral con la encomienda de impulsar alianzas con los liberales radicales. Un año después, el presbiteriano Saúl Vaca Gallegos organizó los primeros reclamos agrarios de cuatro comunidades campesinas dirigiendo la petición al hacendado y presbiteriano Enedino Colín y a otros terratenientes que integraban la Junta. Ante los hechos, en octubre de 1922, al parecer por órdenes de la Junta, fueron asesinados dos agraristas. ${ }^{61}$

Alineados con Múgica, en el mes de abril de 1920 los presbiterianos Moisés Alvarado y Ezequiel María Castillo reclutaron el contingente agrarista conocido con el nombre de "Batallón de Zitácuaro", con el que secundaron el Plan de Agua Prieta desconociendo a Carranza. Esto fue posible debido a la animadversión que los presbiterianos radicales sentían contra Carranza - por el intento de reformar la Constitución en 1918-, a quien

${ }^{99}$ Butler, Popular Piety, p. 98.

${ }^{60}$ Guerra, "El Estado mexicano", p. 192.

${ }^{61}$ Butler, Popular Piety, p. 99. 
le hicieron llegar un escrito firmado por Areli Baca (presidente), León Rodríguez C. (vicepresidente), Andrés C. Pérez (segundo vocal), Graciano Pichardo (tercer vocal) y Enrique M. Reyna (quinto vocal), alineados al Partido Socialista de Michoacán.62 Apoyado por el coronel presbiteriano Cejudo, el Batallón de Zitácuaro recuperó la plaza y el control del Ayuntamiento. Esta fue la última participación de Cejudo al lado de la Junta, que en adelante trató de reforzar los lazos de amistad con Obregón. ${ }^{63}$

La actitud radical anticlerical de los agraristas presbiterianos contra el clero católico se reforzó ante sus prédicas contra que la población aceptara el reparto agrario. En Tuxpan se les acusó de asesinar al presidente municipal, encarcelaron a los sacerdotes y asaltaron a los maestros católicos, lo que ocurrió en octubre de 1921. Las autoridades de Tuxpan se levantaron contra el gobierno del estado culpándolo de los hechos, a lo que el gobernador Múgica respondió enviando un telegrama al general Cejudo, a quien había nombrado jefe del $4^{\circ}$ cuerpo de las defensas civiles

${ }^{62}$ Atendiendo al malestar que estaban causando los artículos anticlericales de la Constitución de 1917, el 21 de diciembre de 1918, Carranza hizo publicar en el Diario Oficial su proyecto de reforma de los artículos 3 y 130 . Respecto del 130, la iniciativa de ley pretendía la derogación de los párrafos que determinaban que las legislaturas de los estados tendrían facultad de establecer según las necesidades locales el número máximo de ministros únicamente de acuerdo con la federación y que para ejercer en México el ministerio de cualquier culto se necesitaría ser mexicano por nacimiento. Respecto del artículo 3, quedaría reformado al señalar que la enseñanza sería laica en los establecimientos oficiales de primaria superior y elemental. Que los planteles particulares solamente estarían sujetos a los programas de inspecciones oficiales, pero que en ellos se podría seguir impartiendo educación religiosa dentro de sus aulas. Los presbiterianos agrupados en el Partido Socialista se mostraron en contra con el argumento de que no era tiempo de hacerlo y emprendieron un severo ataque contra Carranza, a quien le reprocharon no esperar un contexto social más apropiado para "buscar el remedio y aplicarlo con oportunidad y paciencia". "Una reforma importante", El Abogado Cristiano (5 dic. 1918), p. 787. Tres palabras del Partido Socialista. Meyer, La Cristiada, p. 108.

63 Oikión, Los hombres del poder, p. 87. 
y acordadas del departamento de Zitácuaro. En él se le ordenaba preparar a 40 hombres al mando del teniente coronel José María Ávalos, para que salieran hacia Tuxpan a fin de despojar de las armas a los levantados, que ascendían a poco más de 15 individuos. ${ }^{64}$

Este incidente, en el que estuvieron involucradas las defensas civiles, los agraristas y las autoridades locales, suscitó una situación incómoda entre Múgica y el gobierno federal. El problema de fondo fue que, para Obregón, Múgica se atribuía funciones militares que no le estaban permitidas porque las defensas civiles solamente debían servir como apoyo y estar subordinadas al mando federal; por tal motivo Obregón se negó a reconocer a Múgica como el jefe de ellas. Por su parte, para Múgica las tropas federales en Michoacán habían hecho alianzas con los hacendados, evitando de esta forma que se llevara a cabo el reparto agrario, además de estar involucradas en el desarme de las defensas civiles, con lo que se vieron imposibilitadas para hacer frente a las guardias blancas de los terratenientes.

Los enfrentamientos contra el clero y el hecho de que Obregón retirara su apoyo a Múgica para que pudiera hacer frente a la animadversión de los hacendados y terratenientes, hicieron que la administración de Múgica se viera plagada de inconvenientes político religiosos que Obregón prefirió evitar. Finalmente, el incidente sucedido entre los agraristas de Panindícuaro y los hacendados españoles de la Hacienda de Botello, que tuvo como desenlace varios muertos, ocasionaron que Múgica pidiera una licencia para ausentarse del gobierno por un año, quedando a cargo del mismo Sidronio Sánchez Pineda. ${ }^{65}$

El gobierno de Sidronio Sánchez Pineda (1922-1924) fue sumiso a las disposiciones federales y se mantuvo en una línea

${ }^{64}$ AHPEM, Secretaría de Gobierno, Gobernación, Conflictos Políticos, c. 1, exp. 16, ff. 13, 6, 17, 19, 30, Tuxpan. La rebelión del Ayuntamiento (oct. 1921-ene. 1922).

${ }^{65}$ Romero, Historia de la Revolución Mexicana, p. 258. 
moderada y de alianza con los sectores oligárquicos, lo que ocasionó los enfrentamientos más serios en materia de tierras, puesto que fue acusado por los agraristas anticlericales de beneficiar a los hacendados y terratenientes y de impedir que los sectores adheridos a Múgica fueran favorecidos por el reparto agrario. ${ }^{66}$ Además de ello, no terminó de comenzar a aplicar la Ley del Trabajo, dejando a los trabajadores desprotegidos ante los patrones. En materia educativa, el panorama fue desalentador, ya que además de las malas condiciones en las escuelas, éstas disminuyeron de 452 a 398. Finalmente, en materia religiosa Sidronio Sánchez decidió aplicar, en una línea moderada, las leyes anticlericales. ${ }^{67}$

Los enfrentamientos entre los presbiterianos agraristas de Zitácuaro, los hacendados y el clero católico, continuaron hasta finalizar el mandato del gobernador Sidronio Sánchez. Para contrarrestar la labor de los sacerdotes, que apoyados por los hacendados predicaban contra el reparto agrario, formaron el Partido Agrarista Revolucionario de Zitácuaro, con el que se pretendió ejercer presión al gobierno para que agilizara la repartición de tierras y hacer un contrapeso a la Junta. ${ }^{68} \mathrm{La}$ organización del partido recayó en los presbiterianos Ezequiel María Castillo como presidente y Neftalí Novo Cejudo como vicepresidente, además del secretario Abel Santacruz. El programa político constó de 13 propuestas entre las que destacaron: hacer cumplir la Ley Agraria, lo mismo que los artículos 27 y 123, que el reparto de tierras se diera en el menor tiempo posible a todos los pueblos, buscar el mejoramiento social por medio de las escuelas rurales y cumplimentar la Ley del Trabajo. ${ }^{69}$

La amistad conveniente de Cejudo con Obregón y Calles, secretario de Gobernación, le granjeó algunos favores que beneficiaron a los presbiterianos. En septiembre de 1920 Obregón

\footnotetext{
${ }^{66}$ Guerra, "Centralización política”.

67 Oikión, “Las luchas políticas”, pp. 61-64.

68 Butler, Popular Piety, pp. 102-105.

69 “Planes en la nación mexicana. Libro ocho: 1920-1940".
} 
autorizó al presbiteriano Moisés Alvarado gravar las empresas locales de manera extraordinaria para liquidar los gastos del parque y las armas que había utilizado el Batallón de Zitácuaro. ${ }^{70}$ Por petición de Cejudo, en octubre de 1923 Calles destituyó al representante agrario de Curungueo debido a sus nexos con los hacendados y un mes después se quejó ante Calles de que la Junta y las autoridades de Zitácuaro estaban coludidas en el asesinato y encarcelamiento de agraristas, por lo que Calles intervino de manera conveniente para que Sidronio Sánchez tomara las medidas pertinentes. En marzo de 1924 volvió a pedir su ayuda para que los agraristas de Laguna Verde elevaran su ranchería a congregación y así poder solicitar una dotación ejidal, a lo que Calles contestó que recomendaría la petición a las autoridades estatales. ${ }^{71}$

En aras de fortalecer los lazos de clientelismo con Obregón y Calles, los presbiterianos Moisés Alvarado y Neftalí Cejudo acudieron en la defensa de los poderes federales para hacer frente a la rebelión de Adolfo de la Huerta, movilizando, en diciembre de 1923, la reserva agrarista Leales de Zitácuaro. La reserva estuvo compuesta por 70 tropas irregulares y 60 soldados de carrera, que libraron batallas al sur de Guanajuato y en el sitio a Morelia en 1924. Aunque quizá la muestra más evidente de acercamiento entre Cejudo y Obregón fue cuando el presidente ordenó al gobernador deponer a la Junta. Al parecer, el gobernador cumplió la orden en octubre de $1922 .{ }^{72}$

\footnotetext{
70 Oikión, Los hombres del poder, p. 87.

71 Butler, Popular Piety, pp. 100-105.

72 Butler, Popular Piety, p. 104. Los líderes de la Junta siguieron dominando la escena política hasta 1925, cuando recibieron ataques del partido Voluntad Popular, encabezado por el presbiteriano Saúl Gallegos y Fernando Lagunas. En unión del partido José María Morelos, atacaron a la Junta liderada por Arturo Bernal. El problema de fondo, según Oikión, fue el hecho de que Gallegos le imputara a Bernal querer deponer al entonces gobernador del estado, Enrique Ramírez, con el que simpatizaban. Oı́ı́ón, Los hombres del poder, pp. 86-89. Sobre los enfrentamientos entre los liberales carrancistas y la Junta
} 
Coincidimos con Butler cuando señala que el éxito de los agraristas presbiterianos se debió a sus relaciones de amistad con las autoridades federales, a que no tenían sobre sí el peso de la religión católica que los obligaba, por un asunto de conciencia, a no reclamar las tierras de los hacendados, y a que los líderes agraristas fueron personas, además de anticlericales, letradas, lo que ocasionó que el clero local no tuviera injerencia en la conciencia de la población; ${ }^{73}$ población que por otra parte tenía como respaldo ideológico una religión calvinista que la impulsaba a obtener los beneficios sociales que el sistema político podía ofrecerles.

La actitud de los presbiterianos agraristas de Michoacán es particularmente interesante y atípica, puesto que vemos en ellos el legado de una política liberal jacobina y anticlerical que se desarrolló en el siglo xix y que incorporó ciertos valores calvinistas para reclamar el derecho a las tierras que como "elegidos" les pertenecían. Esto a diferencia de algunos metodistas, quienes veían el reparto agrario como un tema "sucio y turbio" originado al calor de una "nefasta revolución”, considerándolo incluso un "asunto político” más que de carácter social “emanado del espantoso zapatismo" ${ }^{74}$

Estas palabras eran pronunciadas en el periódico El Abogado Cristiano en 1929, una década después de que los liberales agraristas y presbiterianos de Zitácuaro no únicamente habían exigido el reparto de tierras sino luchado por ellas. Aunque faltan estudios que esclarezcan la verdadera participación de los protestantes en sus diversas denominaciones, en torno de la política agraria, la nota del Abogado nos permite argumentar que no fue una participación generalizada, que hubo protestantes que no lo aceptaron y tuvieron reservas en cuanto a si era

en la década de 1930 véase Guerra, Del fuego sagrado, pp. 242-247.

73 Butler, Popular Piety, pp. 107-112.

74 "El socialismo cristiano dentro del agrarismo. Por qué no habíamos dicho una palabra sobre tan importante obra”, El Abogado Cristiano (21 mar. 1929), pp. 4-5. 
conveniente hacerlo por el hecho de que era producto de un caos social y político causado por la revuelta armada. Lo anterior también nos sugiere que la participación de los protestantes en el conflicto revolucionario no fue una acción generalizada dentro de las congregaciones, como ya lo hemos argumentado para el caso de Michoacán.

\section{LOS BAUTISTAS ANTE EL ARTÍCULO 27 Y EL FORTALECIMIENTO DEL ANTICLERICALISMO PRESBITERIANO}

Para aplicar los artículos anticlericales, las órdenes de la federación de llevar a cabo las estadísticas sobre los templos y sus anexos continuaron. El 31 de julio de 1922, la Dirección de Bienes Nacionales pidió a las autoridades del estado dar cuenta del nombre de los templos y sus encargados, para lo cual comisionó a varios empleados a fin de que hicieran un inventario general de los bienes inmuebles de propiedad nacional, agregando los templos y sus anexos, "cuales quiera que sea su credo". Dio instrucciones también para que, con base en el artículo 130, las autoridades municipales realizaran la apertura de un libro de registro de los templos y otro de los encargados. ${ }^{75}$

A pesar de la exigencia de los datos, la orden no se cumplimentó puesto que un año después, en agosto de 1923, la Dirección de Bienes Nacionales giró de nueva cuenta instrucciones al gobernador Sánchez Pineda, para que reuniera, de todos los presidentes municipales, las estadísticas requeridas. En respuesta a la circular, las autoridades locales argumentaron haber comisionado a todos los empleados para que se realizara el inventario de los templos y anexos. ${ }^{76}$ En esta ocasión las indagatorias se llevaron a cabo; sin embargo, los datos que se recopilaron de parte

${ }_{75}$ AHHAM, Templos, c. 84, leg. 1, exp. 57, La Dirección de Bienes Nacionales pide el nombre de los templos y sus encargados (jul. 1923).

${ }_{76}$ AHHAM, Templos, c. 84, leg. 1, exp. 57, La Dirección de Bienes Nacionales pide el nombre de los templos y sus encargados (ago. 1923). 
de las autoridades municipales tuvieron serios inconvenientes, lo que ocasionó una serie de vaguedades sobre ellos puesto que en las estadísticas reportadas había omisiones respecto del total de los predios de las iglesias, malas interpretaciones en los datos vaciados, además de faltantes en ellos, lo que llevó a que no se contara con información verídica y confiable. Lo anterior demuestra que las autoridades municipales no realizaron la tarea de manera eficiente, puesto que en algunas ocasiones únicamente se envió el nombre del templo, pero no el culto religioso al que pertenecía. En otras más, no se dio la ubicación exacta del predio y tampoco se incluyó la información requerida sobre los anexos.

De la actitud de las autoridades municipales respecto a las estadísticas que brindaban no podemos decir mucho por la carencia de datos; sin embargo, podemos sugerir que lo hicieran por dos motivos: que en verdad desconocían lo que el gobierno federal les exigía, o bien, que las omisiones se hicieron de manera deliberada dado su particular apego a la religión católica. Así, remitir los datos requeridos significó para las autoridades locales un problema de conciencia, por el hecho de que estarían coadyuvando en detrimento de los bienes del clero católico. Estas actitudes fueron una forma de proceder generalizada, puesto que en los meses de agosto y septiembre de 1923, los datos llegaron a cuentagotas y en ellos únicamente se mencionaban algunas localidades, como por ejemplo las de Chiquimitío, Atécuaro, Jesús del Monte y Charo, diciendo que en ellas "sólo existen templos y capillas católicas"; no se daba tampoco su valor y no se mencionaba si tenían anexos. ${ }^{77}$

Ante estas omisiones, en el mes de septiembre la federación se vio en la necesidad de girar a los presidentes municipales, por múltiples peticiones de ellos, un modelo general en el que se detallaba cómo debía realizarse el inventario de templos. En éste

77 AHHAM, c. 84, leg. 1, exp. 57, Dirección Nacional de Bienes Nacionales, México (sep. 1923). 
se pedía el número total de iglesias en todo el estado, los nombres, el valor aproximado, las categorías sobre si era protestante o católico, la ubicación exacta, cementerios, parroquias y todos los datos de sus anexos. ${ }^{78}$

Respecto a la aplicación del artículo 27, que hablaba de la nacionalización de los bienes de las iglesias, los protestantes se ajustaron a los requerimientos. ${ }^{79} \mathrm{El} 4$ de septiembre de $1922 \mathrm{el}$ misionero bautista Charles L. Neal firmó los papeles de compraventa de la casa donde establecerían el templo protestante a los señores Jesús Jaimes Avilés y su esposa Anselma de la Piedra. Después de conseguir los permisos respectivos ante la Secretaría de Relaciones Exteriores y la Secretaría de Hacienda, la primera certificó haber recibido un escrito en el que el extranjero Neal deseaba comprar el predio de la avenida Francisco I. Madero 596, manzana 5 cuartel 4 de la ciudad de Morelia. Con el propósito de realizar la compra y como "mexicano en cuanto a dicho bien se refiere y en no invocar por lo mismo la protección de mi gobierno sobre éste, bajo la pena en caso de faltar al convenio de perder en beneficio de la nación el bien adquirido [...]", la Secretaría de Hacienda dio el permiso pertinente y el predio fue vendido al misionero bautista. Después de las remodelaciones oportunas, el templo abrió sus puertas al culto público el 5 de septiembre de 1923. No obstante, el inmueble quedó a cargo del pastor mexicano Moisés Arévalo, para no contravenir el artículo 130 constitucional. ${ }^{80}$

\footnotetext{
78 AHHAM, c. 84, leg. 1, exp. 57, Dirección Nacional de Bienes Nacionales, México (sep. 1923).

79 En su fracción II, el artículo 27 federal determinaba que las instituciones religiosas no podrían adquirir, poseer o administrar bienes raíces y los que tenían, pasarían a formar parte de los bienes de la nación, incluidos aquellos inmuebles que estuvieran destinados exclusivamente al culto religioso. En la Constitución estatal de 1918, se dijo respecto del artículo 27, que seguirían las disposiciones constitucionales. "Constitución Política del Estado libre y soberano de Michoacán de Ocampo”, Periódico Oficial (mar. 1918).

80 Sedesol, Municipios, Registro Público de la Propiedad, Iglesia Bautista de
} 
En octubre de 1923, en un escrito enviado por Moisés Arévalo al presidente municipal, le hacía saber que: "en contestación al atento oficio de Usted de fecha 10 de los corrientes, relativo a la forma en que debe darse el aviso de apertura de nuevos templos y de la obligación de remitir 5 copias del acta de apertura del templo citado en: avenida Francisco I. Madero, todos los documentos que Gobernación le requería, así como el aviso de apertura se le habían hecho llegar de manera oportuna a las autoridades". Lo anterior se hacía "siguiendo al pie de la letra lo prescrito por el artículo 130 constitucional, es decir, por triplicado, firmado por el encargado y diez vecinos, razón por la cual se juzga se ha cumplido con lo prescrito". ${ }^{81}$

Aunque no fue una actitud generalizada, porque casi siempre se les otorgó el permiso, al parecer en este caso las autoridades se habían mostrado renuentes a otorgar la aprobación con el pretexto de no haber presentado de manera pertinente "las copias de las actas de apertura", exigiéndole cinco tantos. En esta ocasión Moisés Arévalo se disculpaba "respetuosamente de no haberlas enviado juntamente con el aviso, por no haber hallado ninguna prescripción constitucional a este respecto, ahora que se le ha comunicado que es un requisito indispensable de ley, no tiene inconveniente de someterse a tal disposición y al efecto tiene el gusto de adjuntar al presente escrito las cinco copias de referencia”. La carta, redactada en términos por demás sutiles, terminaba "reiterando a Usted a la vez de las consideraciones, mi más grata subordinación y respeto". ${ }^{82}$

Después de ponerse al corriente en los asuntos administrativos, el predio quedó registrado como Primera Iglesia Bautista

Morelia, exp. 923, Al ciudadano en jefe del Registro Público de la Propiedad del Estado (ene. 1940).

${ }^{81}$ AHHAM, c. 87, exp. 60, Templo Bautista. Emite el Acta de Apertura (oct. 1923).

${ }^{82}$ AHHAM, c. 87, exp.60, Templo Bautista. Emite el Acta de Apertura (oct. 1923). 
de Morelia. ${ }^{83}$ A pesar de que la propiedad fue adquirida con dinero de la misión estadounidense y registrada a nombre de Charles L. Neal, quedó nacionalizada según lo estipulado en el artículo 27. El representante legal y responsable del templo fue Moisés Arévalo, considerando las disposiciones del artículo 130, respecto de que el ministro debía ser mexicano. No obstante, con dinero de la misión se iniciaron las remodelaciones del inmueble atendiendo a dos propósitos: acondicionarla como templo donde llevar a cabo los cultos de la congregación, y además formar otra sección anexa, aunque independiente, la cual sería declarada propiedad particular del extranjero con el número 380. Una vez concluida la remodelación de la segunda sección, que en realidad constituía los anexos del templo, esta fue registrada en el Registro Público de la Propiedad como casa particular del señor Neal.

El propósito de estas modificaciones no fue otro que evitar que el gobierno interviniera el anexo del templo, como lo estipulaba el artículo 27 en su fracción II. De esta forma, convenientemente la misión evitó la nacionalización de la segunda sección que la denominación utilizaba para diversos tipos de reuniones religiosas, además de fungir como casa particular del misionero Neal y de los ministros nacionales. Hecho que contravenía a todas luces las disposiciones constitucionales en materia de nacionalización de templos. ${ }^{84}$

${ }_{83}$ AHHAM, c. 87, exp. 60, Acta de Apertura del Templo de la Iglesia Bautista de esta ciudad a los actos de culto cristiano (oct. 1923).

${ }^{84}$ Esta actitud no fue exclusiva de las iglesias protestantes. Desde 1917 el clero católico ideó mecanismos para evitar la nacionalización de sus bienes poniéndolos a nombre de particulares. Esto ocasionó no pocos inconvenientes a las autoridades, quienes tuvieron el problema de determinar qué propiedades pertenecían a particulares y cuáles a alguna institución religiosa. Recordemos que las propiedades individuales no podían ser confiscadas y que las de las instituciones religiosas eran nacionalizadas sin pago ni indemnización. Además, los gastos de mantenimiento debían correr por cuenta de las propias denominaciones religiosas. Por tal motivo, convenientemente aparecieron propiedades eclesiásticas a nombre de particulares y no fueron la excepción las instituciones 
Cuando en 1923 la Dirección de Bienes Nacionales pidió al gobernador que extendiera la información sobre el nombre de los templos y de sus encargados, además de un minucioso inventario de los anexos, todo con base en el modelo girado desde la federación, la misión bautista únicamente reportó la primera nave, que correspondía al espacio determinado para los servicios de su culto, omitiendo los datos del anexo. Los anexos del templo bautista pasaron inadvertidos por las autoridades por saberse en manos de particulares extranjeros; sin embargo, en 1937 la situación anómala fue denunciada ante las autoridades por un particular. Finalmente después de una larga investigación, que duró tres años, los anexos quedaron incorporados a los bienes de la nación. ${ }^{85}$

Entre los años de 1923 y 1924, la misión bautista trató de promover su crecimiento en el estado mediante reuniones donde se

protestantes. Cumberland, La Revolución Mexicana, pp. 341-342.

${ }_{85}$ En 1934, el ciudadano Wenceslao Gallardo denunció la situación anómala de dichos anexos ante el agente del Ministerio Público Federal adscrito en Morelia. Al parecer, las intenciones de Gallardo eran quedarse con el inmueble; por ello mismo, antes de la denuncia, el apoderado de dichos anexos, Moisés Arévalo, rentó oportunamente una parte a la Compañía Singer de Máquinas de Coser y otra parte se pretendió que fuera rentada a uno de los encargados del templo como casa particular. De esta forma se intentó dar la idea a las autoridades de que se encontraban en manos de particulares. Sin embargo, la estrategia de los bautistas no dio resultado puesto que la Secretaría de Hacienda intervino el inmueble el 12 de diciembre. De esta forma, a pesar de que los misioneros interpusieron una demanda judicial que duró hasta el 14 de junio de 1937, los anexos quedaron incorporados a los bienes de la nación. En el tiempo que duró el proceso de nacionalización los anexos fueron ocupados por el Comité de Propaganda Pro-Gildardo Magaña (1935), la Federación Política Radical Socialista (1936), el Departamento de Asuntos Indígenas (1936) y la Agencia del Banco Nacional Obrero de Fomento Industrial de Morelia (1937). Este mismo año la Procuraduría de Comunidades Indígenas ocupó la nave del templo, donde se instaló un dormitorio para indígenas. Finalmente los anexos fueron recuperados por la junta de vecinos bautista en 1947. AHHAM, c. 84, leg. 1, exp. 57, Templos (1923). David Montemayor, "Primera iglesia bautista de Morelia Michoacán. Un pasado heroico”, México, manuscrito inédito, 2006, pp. 29-58. 
discutió la forma de trabajar, diseminar la propaganda religiosa e impulsar a las sociedades infantiles. ${ }^{86}$ Un año después estableció una tipografía en los anexos no declarados como pertenecientes a la misión, donde se editó la propaganda religiosa bajo la rúbrica de Imprenta Bautista de Morelia. En el taller fueron impresos cientos de folletos, además de algunos sobretiros enviados a otras misiones bautistas, así como libros de texto para las escuelas de las congregaciones, siendo uno de ellos Mirando las regiones, escrito por Susana J. de Arévalo. Dicho libro de propaganda religiosa constaba de 126 páginas divididas en $16 \mathrm{ca}-$ pítulos; fungieron como colaboradoras las misioneras estadounidenses Dra. H. de Neal, May Gilvert, Rebeca R. de Branch, Charles S. Detweiler y A. Derry. ${ }^{87}$ Esto corrobora que dentro de las escuelas protestantes se siguió impartiendo educación religiosa, contraviniendo las disposiciones federales.

Las organizaciones sociales de carácter religioso fueron otro elemento que retomaron las misiones. El 21 de octubre de 1924, la misión bautista fundó en la ciudad de Morelia la Sociedad Femenil Eunice, cuya dirección recayó en Susana J. de Arévalo en conjunción con la misionera estadounidense Annie M. Long. Además, participaron en ella las señoras Ester Bautista, Amelia Fuentes, Socorro Romero, Jesús Sánchez, Sabina Villanueva, Cirila González, Salud Maldonado, Cesárea Rodríguez, Carmen Ruiz, Ascensión Reyes y seis mujeres más. Las actividades de dicha sociedad se circunscribieron particularmente a una labor de tipo religioso, en que las mujeres se encargaron de organizar grupos de estudio y apoyar en la difusión de su doctrina dentro de sus congregaciones. ${ }^{88}$

\footnotetext{
${ }^{86}$ David Montemayor, "Primera iglesia bautista de Morelia Michoacán. Un pasado heroico”, México, manuscrito inédito, 2006, pp. 26-27.

87 David Montemayor, "Primera iglesia bautista de Morelia Michoacán. Un pasado heroico”, México, manuscrito inédito, 2006, pp. 20-21.

${ }_{88}$ David Montemayor, "Primera iglesia bautista de Morelia Michoacán. Un pasado heroico”, México, manuscrito inédito, 2006, pp. 22-26.
} 
Por su parte, los presbiterianos se dedicaron a crear organismos para involucrar de manera activa a las mujeres de las congregaciones, pero ahora no con un sentido político sino enfocadas a una labor netamente religiosa. ${ }^{89}$ Organizaron, a iniciativa de la Iglesia presbiteriana, sociedades femeniles, una de las cuales estuvo a cargo de Arcadia viuda de Pérez como presidenta, secretaria María Pichardo de Arias, vicepresidenta Aurora de Castillo, prosecretaria Eleuteria viuda de Zamano y tesorera suplente Eufrasia viuda de Arias. La labor de las junta femeniles se enfocó exclusivamente a fomentar la actividad religiosa de las mujeres, así como mejorar su desempeño dentro del hogar. ${ }^{90}$

Asimismo, crearon organismos de carácter social y religioso formados por jóvenes, con el propósito de afirmar su doctrina, elevar los principios de la buena moral y educar al pueblo en sus derechos cívicos, puesto que era de vital importancia hacer de los creyentes "los mejores ciudadanos, porque aquellos que respetan la ley de Dios, respetan las leyes del país" . ${ }^{11}$ Una de estas organizaciones fue la Sociedad Cristiana de Jóvenes, encargada de cohesionar a las denominaciones, lograr la unión de objetivos de predicación respecto de las iglesias locales y promover la fraternidad con otras denominaciones evangélicas. ${ }^{92}$ De la misma forma

${ }^{89}$ Entre 1880 y 1910 las presbiterianas habían creado organismos políticos y anticlericales femeniles como: el Club Femenil Josefa Ortiz de Domínguez y Francisca Carrillo, así como la Junta Liberal Leona Vicario, con los que repelieron los ataques del clero católico en su contra. Su máxima participación anticlerical fue su presencia en el Congreso Liberal de 1901. Sobre la participación de las presbiterianas en el congreso y su actividad anticlerical en Zitácuaro véase Mendoza, "Protestantismo liberal".

90 VÁzquez, Los que sembraron, pp. 215-216. "Correspondencia. Jungapeo", El Faro (15 mayo 1899), p. 80 (1º ene. 1900$)$, p. 8 (15 ene. 1900), p. 16.

91 "Qué es lo que la Sociedad de Esfuerzo Cristiano puede hacer a favor del país”, El Faro (15 nov. 1894).

${ }_{92}$ De las sociedades cristianas fundadas durante el porfiriato, hubo dos en Zitácuaro, una en Jungapeo, una en San Francisco Coatepec y una más en el rancho La Colmena. Además, había otras dos instituidas en las rancherías de Silva y Santa María, todas ellas fundadas desde la década de 1900. Hubo otra 
actuaban para buscar mecanismos de ayuda en favor de promover la manera en que se debían estudiar los textos bíblicos. ${ }^{93}$

El clero católico no estaba conforme con lo que consideró el avance del protestantismo en el estado, que era causa de que los fieles se separaran del culto católico para unirse a las filas de las iglesias protestantes. Los esfuerzos del clero se enfocaron principalmente en Zitácuaro, donde según el cura Manuel Vargas, enviado por las autoridades eclesiásticas en 1922, el crecimiento de las escuelas presbiterianas era alarmante debido a que cada congregación tenía una. Para contrarrestar la influencia del protestantismo se organizó una Asociación Católica de la Juventud Mexicana. ${ }^{94}$ Este esfuerzo se sumó a la lucha del obispo de Tacámbaro, Leopoldo Lara y Torres, quien en julio de 1921 se refería al protestantismo como un explotador de la pobreza de nuestro pueblo que "viene a comprar nuestra fe con un puñado de dólares [...] y lo que es [...] más satánico, a arrebatarnos a nuestros niños". ${ }^{95}$

En 1923, el arzobispo Ruiz y Flores lanzó una instrucción pastoral en la cual advirtió a la sociedad de los errores del protestantismo y ordenó que fuera clavada en todas las puertas de los templos de la arquidiócesis. En ella decía que las iglesias protestantes no eran católicas, no eran apostólicas y que sus comuniones no eran verdaderas. Asimismo, prohibió a los católicos asistir

en Tuzantla, establecida el 19 de marzo de 1906, con el nombre de Providencia. En 1901, la Sociedad de San Francisco Coatepec mencionaba resultados muy alentadores: el 24 de septiembre de 1901 había cumplido dos años, con una actividad palpable en la distribución de los bienes de salvación y de los trabajos presbiterianos en el distrito. "Lo que puede hacer una Sociedad de Esfuerzo Cristiano en la Iglesia”, El Faro (15 sep. 1901), p. 139; (1ํoct. 1901), p. 147; (15 oct. 1906), p. 168; (1 ${ }^{\circ}$ jul. 1900), p. 99; (13 ago. 1909), p. 527.

93 "Sociedad de Esfuerzo Cristiano", El Faro (15 mayo 1892), p. 79. "El ori-

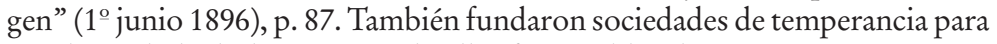
erradicar el alcoholismo. Una de ellas fue establecida en Jungapeo en 1903. "La temperancia en México", El Faro (15 oct. 1888), p. 155. "Convención de Patámbaro" (1o oct. 1902), p. 146.

${ }^{94}$ Butler, Popular Piety, pp. 185-188.

${ }^{95}$ Lara y Torres, Documentos para la historia, p. 7. 
a cualquier acto de culto protestante so pena de excomunión. Las recomendaciones del arzobispo obedecieron a los enfrentamientos sucedidos en varias partes del estado entre católicos y protestantes; se sabía, por ejemplo, que en el pueblo de Ocampo "la descatolización de la sociedad" iba en aumento puesto que en 1923 no se habían registrado matrimonios católicos y los evangelizadores predicaban por todo el distrito repartiendo volantes, biblias heréticas y formando congregaciones. Aun así, las muestras de intolerancia hacia los protestantes no eran gratis, sobre todo en el oriente del estado, el cual fue testigo de serias muestras de anticlericalismo por parte de los presbiterianos, quienes se volcaron contra los curas párrocos locales de manera violenta. ${ }^{96}$

En 1919, en Jungapeo, un grupo anticlerical había incendiado el curato e invadido el templo. Al año siguiente se expulsó de manera violenta a los curas católicos de la población para que los protestantes pudieran ejercer libremente su religión. En Tuzantla quemaron los templos y en Zitácuaro se cerraron las puertas de los mismos con tablas y clavos. En Ocampo, en 1921 le escupieron al cura párroco en la cara y atacaron a los católicos que lo acompañaban, y en otra ocasión siguieron al sacerdote tirándole piedras, además de proferirle insultos. Asimismo, en Chichimequillas, en 1923, en franca confrontación con el clero los presbiterianos pavimentaron el atrio del templo y lo adaptaron para ser una cancha de baloncesto. En mayo de 1924, en Tuzantla se expulsó y encarceló al padre Montero por orden de las autoridades de Zitácuaro. Dicho incidente se atribuyó a la obra de los anticlericales protestantes. ${ }^{97}$

Con este panorama de intolerancia religiosa de parte de protestantes y católicos, en un contexto de enfrentamientos entre las autoridades y el clero que estaba escalando peldaños peligrosos en el ámbito federal, terminó la gubernatura de

96 Butler, Popular Piety, pp. 185-188.

97 Butler, Popular Piety, pp. 183-206. 
Sidronio Sánchez Pineda. El conflicto entre las autoridades y el clero católico en Michoacán estaba lejos de desaparecer; llegó a su máxima expresión durante el gobierno de Enrique Ramírez, quien tuvo que afrontar el conflicto cristero que modificó la religiosidad y sentó las bases necesarias para una nueva diversificación del campo religioso ante el establecimiento de las primeras iglesias de tipo pentecostal.

\section{CONCLUSIÓN}

La política anticlerical en Michoacán estuvo condicionada por los intereses locales de las autoridades y la forma en que el clero católico reaccionó contra la Revolución y contra las leyes constitucionales, aplicándolas a discreción según sus convicciones político religiosas. De esta forma, aunque el contexto de los acontecimientos dictaminó una actitud enérgica contra cualquier religiosidad establecida en el estado, en la práctica no se cumplimentó la orden, dejando cierto margen de acción a los protestantes.

Podemos afirmar entonces que la política religiosa de Múgica y Sánchez Pineda fue de tolerancia ambigua hacia las iglesias protestantes, no porque fueran partidarios del protestantismo, sino como resultado de que éstas decidieron acatar de manera conveniente las disposiciones en materia religiosa. Por lo anterior, los protestantes no fueron considerados una amenaza al orden constitucional, toda vez que se mostraron obedientes en respetar las leyes que regulaban su presencia en el estado. No obstante, haberse alineado a las medidas anticlericales de las autoridades en turno no fue un obstáculo para idear mecanismos tendientes a conservar sus bienes y evitar que fueran nacionalizados, logrando muchas veces burlar la vigilancia de las autoridades.

Las congregaciones protestantes actuaron de manera acomodaticia en determinadas situaciones, siendo una de ellas el tema 
del reparto agrario. En este sentido, los presbiterianos, a diferencia de los bautistas, se involucraron en la lucha por la tierra agrupados en organismos políticos con una ideología particular en la que se entremezclaron ideales calvinistas y liberales. Esta participación política de los presbiterianos se hizo de manera particular atendiendo a sus intereses de clase; no fue una participación generalizada ni que tuviera que ver con la misión estadounidense. Si bien la misión se mantuvo respetuosa del actuar de algunos presbiterianos, no los juzgaron porque desde su punto de vista, ante las injusticias sociales los individuos tenían el derecho civil de actuar. El pensamiento calvinista le dio a la lucha por la reforma agraria un matiz particular que les permitió, según Butler, justificar los actos de violencia en el derecho a la tierra como individuos elegidos por Dios. Desde mi punto de vista, los hacendados, los terratenientes y el clero fueron vistos por los presbiterianos como el enemigo que quería ver al campesino sumido en la miseria y resignado a vivir bajo la amenaza de que cambiar esta situación significaría ir contra Dios; por ello, recibir tierras y luchar por ellas era parte de la certeza moral de que Dios estaba de su lado, y la clara evidencia de ello eran las posesiones y bienes terrenales que mediante el trabajo y demandas justas podían adquirir para mejorar su estatus social y económico. Esta manera de pensar se ve reflejada en sus discursos anticlericales emitidos en la prensa liberal y protestante y en la instrucción liberal impartida dentro de las escuelas, que fueron espacios donde se concientizó al pueblo para hacer valer sus derechos y obligaciones respecto de las leyes.

En referencia a los artículos 3, 27 y 130 de la Constitución federal, que afectaban a las iglesias protestantes en el tema de la educación, la nacionalización de los templos y la presencia de extranjeros en las congregaciones, las misiones en Michoacán no se vieron afectadas. Los espacios educativos continuaron abiertos, dirigidos por profesores extranjeros, e impartiendo educación religiosa. Los bautistas fundaron sus primeros colegios, mientras 
que los presbiterianos impulsaron el amor a la tierra y a lo nacional por medio de la creación de escuelas rurales, conservando además las escuelas de primeras letras. Si bien el alcance de estos espacios fue reducido, puesto que la escuela rural se circunscribió a los miembros de las congregaciones, fue una opción para incentivar una conciencia agrarista. Finalmente, aunque violentaban el artículo 130, las congregaciones eran dirigidas por predicadores extranjeros y los templos, aunque pasaron a manos de nacionales para efectos legales, seguían recibiendo ayuda económica y religiosa que llegaba por medio de los misioneros estadounidenses.

Por último, bajo la certeza de que las medidas anticlericales en el estado no estaban enfocadas hacia ellos, los protestantes orientaron sus esfuerzos a la creación de espacios sociales para competir con el clero católico por los bienes de salvación y reforzar entre la sociedad ciertas normas éticas y morales, como la abstinencia de alcohol. La fortaleza del protestantismo durante este periodo se vio reflejada en el aumento de un anticlericalismo radical presbiteriano, que llegó a conatos de violencia contra el clero católico del estado. Si bien este anticlericalismo ya existía desde el porfiriato, lo cierto es que no había traspasado las fronteras de la prensa liberal y confesional protestante. Esta dinámica de enfrentamientos radicales entre protestantes y católicos originó más tarde, durante el gobierno de Enrique Ramírez, la expulsión de congregaciones bautistas en algunas localidades.

\section{SIGLAS Y REFERENCIAS}

AHHAM Archivo Histórico del Honorable Ayuntamiento de Morelia, Mich., México.

AHPEM Archivo Histórico del Poder Ejecutivo de Michoacán, México. AHIMMAR Archivo Histórico de la Iglesia Metodista de México A. R., México.

Baldwin, J. Deborah, Protestants and the Mexican Revolution. Missionaries, Ministers, and Social Change, Urbana y Chicago, University of Illinois Press, 1990. 
BASTIAn, Jean-Pierre, Los disidentes. Sociedades protestantes y revolución en México, 1872-1911, México, Fondo de Cultura Económica, El Colegio de México, 1989.

BRITTON, John, “Moisés Sáenz: nacionalista mexicano”, en Historia Mexicana, xxII: 1 (85) (jul.-sep. 1972), pp. 77-97.

Butler, Matthew, Popular Piety and Political Identity in México's Cristero Rebellion: Michoacán, 1927-29, Nueva York, The British Academy, Oxford University Press, 2004.

"Crónicas y debates de las sesiones de la Soberana Convención Revolucionaria", compilador: Florencio Barrera Fuentes, Integrantes de la Soberana Convención Revolucionaria en la ciudad de Aguascalientes, en www.antorcha. net/biblioteca_virtual/historia/soberana/1_1.html. Consultado el 20 de agosto de 2016.

Cumberland, Charles, La Revolución Mexicana, los años constitucionalistas, México, Fondo de Cultura Económica, 1992.

Dorantes González, Alma, "Una asociación protestante en el Jalisco revolucionario: entre el respeto a la norma y la conflictiva realidad", en Takwá, Historiografías, 13 (primavera 2008), pp. 61-82.

Duarte Soto, Crispín, Zitácuaro. Memoria fotográfica, México, edición del autor, 2005, t. I.

Florescano, Enrique (coord.), Historia general de Michoacán, t. IV, El siglo XX, México, Gobierno del Estado de Michoacán, Instituto Michoacano de Cultura, 1989.

Fuentes BazÁn, Ma. Eugenia, "Los estudiantes del Instituto Metodista Mexicano y la Revolución Mexicana”, en Dimensión Antropológica, 6, 17 (sep.-dic. 1999) http://www.dimensionantropologica.inah.gob.mx/?cat=74. Consultado el 8 de julio de 2016.

Guerra Manzo, Enrique, "El Estado mexicano y el faccionalismo político: Zitácuaro, Michoacán, 1928-1940”, en Política y Cultura, 29 (2008), pp. 191215.

Guerra Manzo, Enrique, "Centralización política y grupos de poder en Michoacán, 1920-1940”, en www.redalyc.org/html/267/26701611/. Consultado el 14 de octubre de 2016.

Guerra Manzo, Enrique, Del fuego sagrado a la acción cívica. Los católicos frente al Estado en Michoacán (1920-1940), México, El Colegio de Michoacán, Universidad Autónoma Metropolitana, 2015. 
Guerra Manzo, Enrique, "Hombres y mujeres de Zitácuaro", en www. zitacuaro.gob.mx.htm. Consultado el $1^{\circ}$ de abril de 2016.

"Iglesia Nacional Presbiteriana de México", en www.presbiterianosag.com. mx/wpcontent/uploads/2014/07/Revista-especial-INPM.pdf. Consultado el 3 de marzo de 2016.

Lara y Torres, Leopoldo, Documentos para la historia de la persecución religiosa en México, México, Jus, 1972.

Libro conmemorativo de las bodas de diamante de la Iglesia presbiteriana en México, 1872-1947, México, Reforma, 1947.

Libro de Registro de la Iglesia Presbiteriana Getsemaní de Zitácuaro, años de 1877-1890.

Libro Histórico del Sínodo General de la Iglesia Presbiteriana de México, México, 1901-1951, México, El Faro, 1956.

Mendoza García, Leticia, "Instrucción cívica y liberal del presbiterianismo en el distrito de Zitácuaro, 1894-1902”, en Tzintzun, 54 (jul.-dic. 2011), pp. 53-92.

Mendoza García, Leticia, "Política religiosa en Michoacán. Las diversidades evangélicas, 1910-1932", tesis de doctorado en historia, Michoacán, Universidad Michoacana, 2015.

Mendoza García, Leticia, "Protestantismo liberal en Michoacán. El presbiterianismo en el distrito de Zitácuaro 1877-1901”, tesis de maestría en historia, Michoacán, Universidad Michoacana, 2011.

Meyer, Jean, La Cristiada. La guerra de los cristeros, México, Siglo Veintiuno editores, 2012, t. II.

1872-1972 Centenario: Iglesia Nacional Presbiteriana de México, México, Comité Pro-Centenario, 1973.

Nueva Edición del Diario de Debates del Congreso Constituyente de 19161917, México, Suprema Corte de Justicia de la Nación, 2006, t. I.

Oı́ı́ón Solano, Verónica, "Las luchas políticas y las vicisitudes de los ideales revolucionarios, 1920-1928”, en FLORESCANO (coord.), 1989, t. IV, pp. 53-71.

Oikión Solano, Verónica, Los hombres del poder en Michoacán, 1924-1962, Michoacán, El Colegio de Michoacán, Universidad Michoacana de San Nicolás de Hidalgo, 2004. 
Pérez Escutia, Ramón Alonso, La Revolución en el oriente de Michoacán 1900-1920, México, Universidad Michoacana de San Nicolás de Hidalgo, 2007. "Planes en la nación mexicana. Libro ocho: 1920-1940", en www.archivos. juridicas.unam.mx/www/bjv/libros/6/2983/6.pdf. Consultado el 25 de mayo de 2015.

Romero Flores, Jesús, Historia de la Revolución Mexicana, México, Costa Amic, 1975.

SÁnchez Díaz, Gerardo, "Los elementos y las acciones de la contrarrevolución en Michoacán, 1912-1923”, en J. N. GuZMÁn Ávila et al., La Revolución en Michoacán, 1920-1926, Michoacán, Universidad Michoacana de San Nicolás de Hidalgo, 1987, pp. 105-118.

Sánchez Rodríguez, Martín, Grupos de poder y centralización política en México: el caso de Michoacán, 1920-1924, México, Instituto Nacional de Estudios Históricos de la Revolución Mexicana, 1993.

Sсотт, Luis, La sal de la tierra: una historia socio-política de los evangélicos en la cindad de México, 1964-1991, México, Kyrios, 1991.

Teja Andrade, Jesús, Zitácuaro. Monografías municipales del estado de Michoacán, México, Gobierno del Estado de Michoacán, 1978.

Tres palabras del Partido Socialista Michoacano. El 5 de febrero en la H. Zitácuaro, las reformas a los artículos $3^{\circ}, 27^{\circ}, 123^{\circ}$ y $130^{\circ}$, Zitácuaro, 5 de febrero de 1919.

Treviño, Alejandro, Historia de los trabajos bautistas en México, México, Casa Bautista de Publicaciones, Convención Nacional Bautista de México, 1939.

VÁzquez, Apolonio, Los que sembraron con lágrimas, apuntes históricos del presbiterianismo en México, México, El Faro, 1985.

"YMCA México", en www.ymca.org.mx/historia.html. Consultado el 15 de agosto de 2016. 